\title{
Literature Review of Lighting Standards
}

Philip A. Sanders

Building and Fire Research Laboratory

Gaithersburg, Maryland 20899

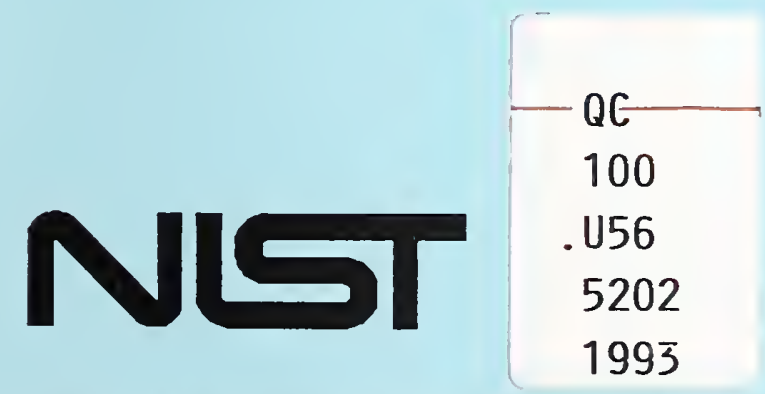

United States Department of Commerce

National Institute of Standards and Technology 



\section{Literature Review of Lighting Standards}

Philip A. Sanders

June 1993

Building and Fire Research Laboratory

National Institute of Standards and Technology

Gaithersburg, MD 20899

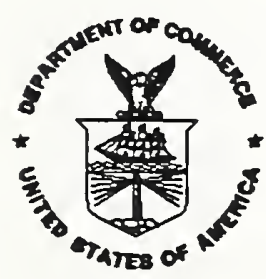

United States Department of Commerce

Ronald H. Brown, Secretary

National Institute of Standards and Technology

Arati Prabhakar, Director
Prepared for:

Canadian Standards Association

Toronto, Canada 


\begin{abstract}
Society's dependence on energy and increased concerns about global warming have prompted legislative bodies to implement minimum energy efficiency requirements for architectural lighting systems. The present report reviews and summarizes current Canadian and US federal legislation, US state legislation and model energy efficiency codes with particular attention to describing the minimum conformance standards. Although early state legislation regulates the efficiency of complete lighting systems, more recent Canadian and US federal legislation stipulates minimum efficiencies for individual lighting system components. However, since the minimum component efficiencies are based on testing protocols that do not permit an accurate assessment of the electrical and thermal interactions of components in an installed lighting system and since component requirements are becoming increasingly stringent, the need exists to develop more comprehensive testing procedures. Therefore, the present report also reviews the current national, international, and industry testing procedures identifying inconsistencies and deficiencies which lead to inaccurate performance assessments so that these may be addressed in future testing protocols. Finally, the review outlines a framework for developing more comprehensive test procedures.
\end{abstract}

Keywords: Lighting; efficiency; test methods; regulation; systems; lamps; ballasts; luminaires; photometry; building technology 


\section{Acknowledgments}

The author would like to thank Drs. Belinda Collins and Steve Treado for their insightful contributions throughout the project; and Mr. Colin Bardell for his help and patience in seeing this project through to its completion. 
List of Tables .vii

1. Introduction. 1

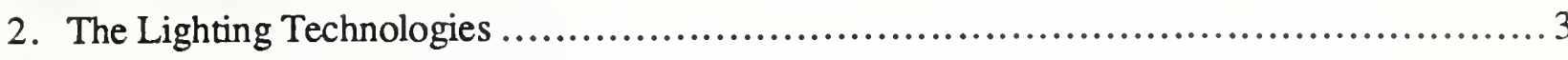

2.1 Lamps ..................................................................... 3

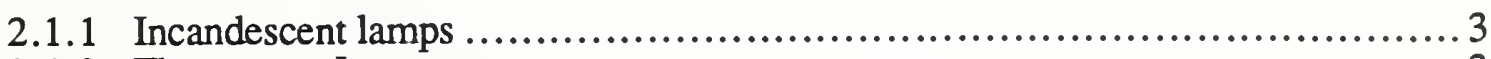

2.1.2 Fluorescent Lamps...................................................... 3

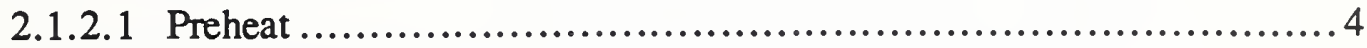

2.1.2.2 Instant Start........................................................ 4

2.1.2.3 Rapid Start.................................................... 5

2.1.3 High Intensity Discharge Lamps ........................................ 5

2.1.3.1 High Pressure Mercury Vapor ......................................5

2.1.3.2 Metal Halide .........................................................6 6

2.1.3.3 High Pressure Sodium Vapor .....................................6 6

2.2 Ballasts ........................................................................ 6

2.2.1 Electromagnetic Ballasts..........................................................7

2.2.2 Electronic Ballasts...................................................... 7

2.3 Fixtures............................................................................... 7

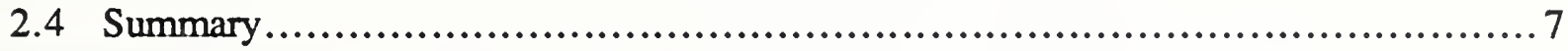

3. Testing Methods and Standards....................................................... 8

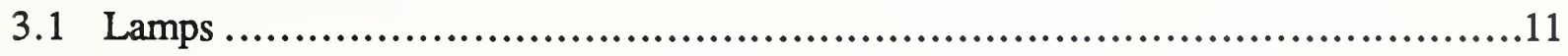

3.1.1 Electrical measurements ..................................................11

3.1.1.1 Incandescent.......................................................11

3.1.1.2 Tubular Fluorescent Lamps..............................................11

3.1.1.3 Self-Ballasted Lamps .................................13

3.1.1.4 Compact Fluorescent ...............................................13

3.1.1.5 High Intensity Discharge...............................................16

3.1.1.5.1 High Pressure Mercury Vapor..........................16

3.1.1.5.2 Metal Halide.................................................16

3.1.1.5.3 High Pressure Sodium......................................19

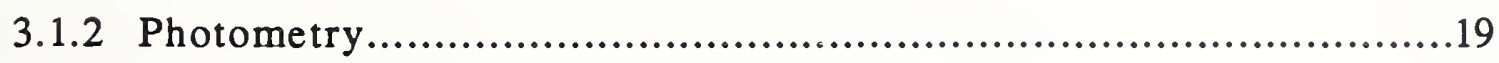

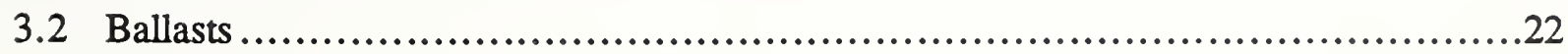


3.2.1 Ballasts for Fluorescent Lamps.................................................23

3.2.1.1 Electromagnetic Ballasts ........................................23

3.2.1.2 Electronic Ballasts .................................................24

3.2.3 High Intensity Discharge Ballasts........................................26

3.3 Luminaires ......................................................................26

3.4 Summary and Discussion ......................................................... 28

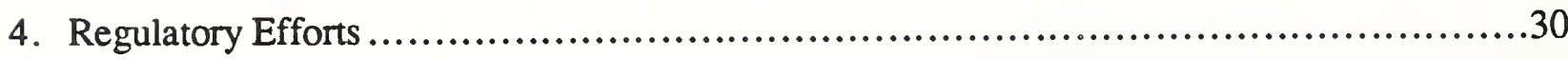

4.1 Canadian Energy Efficiency Act............................................................30

4.2 US Federal Lighting Equipment Legislation .......................................32

4.2.1 National Appliance Energy Conservation Amendments of $1988 \ldots \ldots \ldots \ldots \ldots \ldots . .32$

4.2.2 Comprehensive National Energy Policy Act....................................33

4.3 ASHRAE/IES Standard 90 ........................................................33

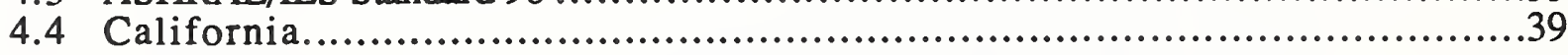

4.4.1 Mandatory Requirements......................................................41

4.4.2 Determining Building Compliance ...........................................44

4.4.2.1 Prescriptive Approach to Determining Allowed Lighting Power........42

4.4.2.1.1 Complete Building Method...................................42

4.4.2.1.2 Area Category Method......................................42

4.4.2.1.3 Tailored Method ..............................................45

4.4.2.2 Performance Approach to Determining Allowed Lighting Power........45

4.4.2.3 Determining Actual Lighting Power .................................47

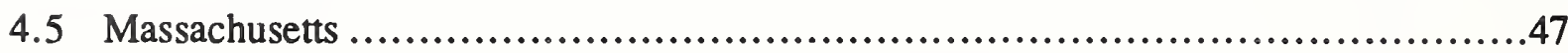

4.5.1 Individual System Compliance - The Lighting System.......................47

4.5.2 Design by System Analysis................................................49

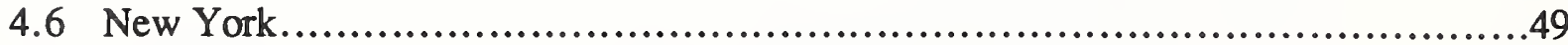

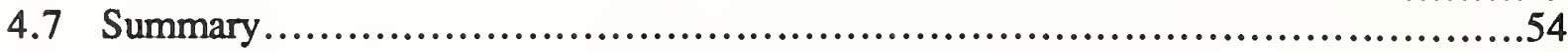

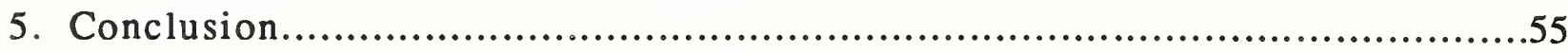

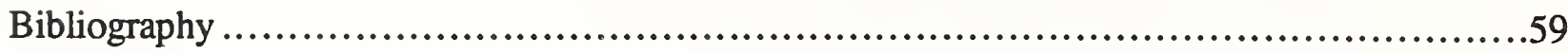

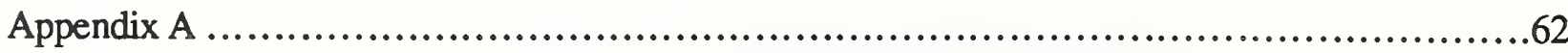

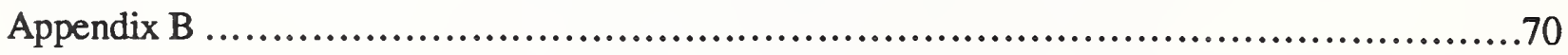

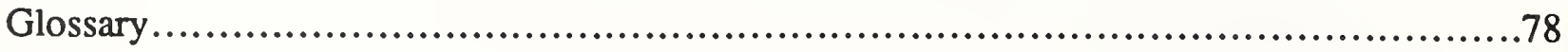




\section{List of Tables}

Table 1. Availability of Test Methods for Differing Lighting Technologies

from Various Standards Organizations.

Table 2. Summary of Stipulated Operating Conditions Affecting Tubular

Fluorescent Lamp Output.

Table 3. Summary of Stipulated Operating Conditions Affecting Self-

Ballasted Lamp Output.

Table 4. Summary of Stipulated Operating Conditions Affecting Compact

Fluorescent Lamp Output. ...

Table 5. Summary of Stipulated Operating Conditions Affecting High

Pressure Mercury Vapor Lamp Output.

Table 6. Summary of Stipulated Operating Conditions Affecting Metal

Halide Lamp Output.

Table 7. Summary of Stipulated Operating Conditions Affecting High

Pressure Sodium Lamp Output.

Table 8. Summary of Operating Conditions for Obtaining Reliable

Photometric Measurements from Discharge Sources.

Table 9. Summary of Operating Conditions for Obtaining Reliable

Performance Measures from Electromagnetic Ballasts for

Fluorescent Lamps.

Table 10. High Intensity Discharge Ballasts.

Table 11. An Overview of the Legislative Intent of US Federal and State

Energy Legislation.

Table 12. US and Canadian Minimum Ballast Performance Requirements.........................34

Table 13. US Fluorescent Lamp Efficiency Requirements. ................................ 35

Table 14. US Incandescent Reflector Lamp Efficiency Requirements. ........................36

Table 15. Prescriptive Unit Lighting Power Allowance (ULPA), $\mathrm{W} / \mathrm{m}^{2}$

Gross Lighted Area of Total Building.

Table 16. Control Types and Equivalent Control Points.

Table 17. Maximum Power Densities for Buildings Based on General

Use.

Table 18. Maximum Power Densities for Spaces Based on General Use 
Table 19. Power Density for Illuminance Categories F Through I as a Function of Task Area and Throw Distance.

Table 20. Minimum Efficacies and Color Rendering Indexes for Certain Fluorescent Lamps Required by The New York Energy Code............................51

Table 21. Minimum Ballast Performance Requirements Required by The New York Energy Code .52

Table 22. New York Total Luminaire Efficiency, Minimum Performance. .53 


\section{Literature Review of Lighting Standards}

\section{Introduction}

The 1973 oil embargo captured the attention of the world and demonstrated the overwhelming dependence of today's society on energy. Since then concerted efforts have been undertaken to conserve energy by developing and implementing alternative energy supplies, and improving the energy efficiency of existing technologies. More recently these efforts have intensified with environmental concerns of increased global warming due to the "Greenhouse Effect". One specific industry showing promising opportunities for increased energy conservation is lighting. In fact the US Department of Energy's Energy Information Administration (1992) estimates that up to 75 percent of the energy used for lighting in commercial buildings could be conserved by implementing technologies already on the market. While this particular estimate is a bit ambitious in some of its assumptions, assuming that all general service incandescent lamps are replaced with compact fluorescent lamps and that lighting levels are reduced by 25 percent for example, it nevertheless indicates that there are significant opportunities for conserving energy.

Recognizing that opportunities for conservation exist, government, industry and utilities have been working together on developing different strategies for improving energy efficiency. For example, because increasing demands are being placed on utilities to supply more electricity during business hours to meet the demands of the electronic office, utilities are faced with building expensive new power plants or offering customers incentives to shed some of their demand load during peak business hours. The most attractive and feasible solution is to offer energy saving incentives to customers. Often these incentives involve the customer installing newly purchased "energy efficient" equipment with the promise from the utility that the cost savings in decreased energy usage will offset the initial cost of the equipment or utilities will offer rebates toward the purchase of new equipment.

In addition to voluntary incentive initiatives, another strategy to limiting energy consumption is regulation. When it became clear to the United States in the early ' 70 s that secure energy supplies were going to become very important, the country became a world leader in defining energy efficiency standards. The American Society of Heating, Refrigerating and Air-Conditioning Engineers (ASHRAE) assumed responsibility for developing a national voluntary consensus energy conservation standard, known as Standard 90 , intended for use in designing new buildings with the exception of low-rise residential structures. Standard 90 outlines prescriptive and performance criteria for the building's heating, ventilating and air-conditioning (HVAC), building envelope, lighting, and service water heating systems. Since its introduction, Standard 90 has served as the technical base for energy conservation sections of regional building codes and, as such, has been enacted in one form or another by each of the fifty states as the regulatory document for energy conservation in buildings. Some state initiatives have been more noteworthy than others, however. Specifically, California, New York and Massachusetts have enacted rather strict, more prescriptive guidelines for energy conservation.

Although much of the individual state's energy legislation traditionally attempted to ensure the energy efficiency of lighting systems by limiting a lighting system's power consumption, recent federal legislation includes performance criteria for individual system components under the United States Federal Government energy conservation initiative. This initiative aims to establish minimum efficiencies for lighting equipment commonly found in buildings in several stages. The first component to be regulated was ballasts for fluorescent lamps. More recent legislation establishes minimum efficiencies for incandescent and fluorescent lamps while future legislation is expected to regulate high-intensity discharge (HID) lamps and luminaires in general. 
There are two approaches to regulating energy consumption: the system approach, which limits the power density $\left(\mathrm{W} / \mathrm{m}^{2}\right)$ of a lighting system, and the component approach, which limits the minimum rated performance of individual lighting components. Despite the fact both approaches are dissimilar in their method, they are both built upon the same faulty premise. Both approaches inappropriately assume that the actual performance characteristics of lighting systems and components are the same as their rated characteristics. Unfortunately, rated performance characteristics are often very different from actual performance characteristics because of the incomplete nature and the sometimes inappropriate application of testing methods used to characterize system and component performance.

Standard testing methods used to rate performance characteristics have been in existence for many years, long before the desire to regulate energy consumption of lighting systems. The goal of standardized test methods is to prescribe procedures whereby repeatable measurements can be made which ensure the reliability of published performance data and to establish minimum performance requirements for individual lighting components operating under very controlled laboratory conditions. With one exception, the Canadian National Standard for measuring fluorescent lamp ballast efficacies (CAN/CSA-C654-M91), these standard test methods do not establish minimum efficiency requirements. Rather, they simply establish the procedure to be used to measure efficiencies which then may be regulated by law. As such, standards do not permit the characterization of the intricate nature of component interactions, which are fully recognized as being major contributors to the performance and energy consuming nature of lighting systems. As a simple example, consider the light generating capacity of fluorescent lamps.

Efficacy is the ability of a lamp to convert its input power to light. It is described as the number of lumens produced for each watt of power consumed. The rated light output of a fluorescent lamp is determined when the lamp is operating at room temperature without an enclosure and powered by a very controlled power source. It is well known, however, that fluorescent lamp output, and thus efficacy, is very sensitive to temperature changes (Kaufman, 1984, p8-28). Therefore, the actual light output of the lamp enclosed in a luminaire which inhibits heat dissipation will be much different from the rated light output. Consequently, installed efficacy is not equal to rated efficacy.

If the rated efficacy of a light source is different than its installed efficacy and if lighting systems are designed based on rated values, it follows that predictions of the amount of light produced by an installed system for the energy consumed are likely to be inaccurate. Therefore, test procedures which address the intricate relationship between components and which accurately characterize total system performance are needed. Data from such procedures would allow a more accurate assessment of energy conservation guidelines. This assessment may reveal that the legislation currently in place is either too liberal or too restrictive. In either case, this judgment is impossible without the capacity to accurately predict system performance.

This report addresses the problems associated with using rated, as opposed to measured, performance data to regulate the energy consumption of lighting systems. It describes in some detail how the different lighting components work with considerable emphasis placed on the operating characteristics that determine the quantity of light produced by a system. Then, from an international and national perspective, it describes test methods currently used to rate lighting components and regulatory efforts for lighting systems.

The test methods section describes the basic test methods for the various lighting components, including lamps, ballasts, and luminaires. Within each technology, the test methods published by major standards organizations are summarized in table format allowing the technical gaps and inconsistencies to be identified more easily. 
Following the test methods section is the regulatory section. The regulatory section begins with descriptions of the Canadian Energy Efficiency Act and the US Federal Legislation before continuing with descriptions of the energy use sections of state building codes relating to lighting system design from California, Massachusetts, and New York. ASHRAE/IES Standard 90 is also discussed because it has been incorporated into the building codes of many other states.

The report closes with a summary demonstrating the importance of developing a testing method which accurately addresses component interactions so that a strong base can be established for building more solid legislation, including a framework for developing such a procedure.

This document only addresses lighting equipment used in commercial interiors. Specifically, this includes all luminaires, lamps and ballasts, with the exception of low pressure sodium equipment. Low-pressure sodium equipment is excluded because its color qualities render it inappropriate for commercial environments.

\section{The Lighting Technologies}

Lighting systems are composed of components including lamps, ballasts, fixtures and controls. To develop accurate test methods and regulatory legislation, it is helpful to have an understanding of how each of these components operates and, more importantly, each interacts with the others.

\subsection{Lamps}

There are basically two types of lamps - incandescent and gas discharge - distinguished by the means invoked to convert electrical energy to heat and light. Incandescent lamps generate light by heating a solid. Gas discharge sources, including fluorescent and high intensity discharge lamps, generate light by one of two methods. The first and simplest method which is unique to high intensity discharge sources is to excite a gas which produces discrete line spectra. The second method is to excite a gas resulting in the production of ultraviolet energy which is absorbed by the phosphor coating on the lamp's bulb and re-radiated in the visible spectrum. Depending upon the light generating characteristics of the phosphor coating, the second method will produce a continuous spectrum of visible light that is more uniformly distributed across the visible spectrum.

\subsubsection{Incandescent lamps}

Incandescent lamps are the oldest and simplest lamp manufactured. In general, they consist of a tungsten filament supported inside a glass bulb sealed with a base. As part of the manufacturing process, the air is evacuated from the bulb and replaced with an inert gas. The inert gas prevents the filament from evaporating during operation. Incandescent lamps are the most inefficient lamps because they convert a larger portion of their input power to heat and the majority of the generated optical radiation is in that portion of the spectrum to which the eye is relatively insensitive.

Because incandescent lamps are incandescent resistors much like electric stove burners, light output varies with fluctuations in the power supply but is unaffected by environmental conditions such as temperature.

\subsubsection{Fluorescent Lamps}

Fluorescent lamps, or low pressure mercury vapor lamps as they're sometimes called, consist of a single glass tube coated on the inside with a phosphor coating and sealed at both ends with a filament or electrode assembly that is coated with an electron emissive material. Similar to incandescent lamps, the tube is evacuated of air and filled with an inert gas at low pressure. In addition, a very small amount of mercury is introduced to the tube. 
Two types of fluorescent lamps are commonly used in commercial applications. The first is the common tube, straight or U-shaped, with diameters ranging from 15 to $54 \mathrm{~mm}$ and lengths ranging from 0.15 to $2.4 \mathrm{~m}$. The second configuration is the compact fluorescent. Compact fluorescent lamps are much smaller than tubular fluorescent lamps and generally have a long, slender singleended U-shaped configuration. The diameter of the tube used to form the U-shape is about $13 \mathrm{~mm}$ and the length of the "U" varies from 80 to approximately $575 \mathrm{~mm}$. In addition, compact fluorescent lamps may be composed of one or two "U's" and are referred to as twin- or quad-tube lamps respectively.

Fluorescent lamps generate light through a gas discharge process beginning when an arc is struck between the two electrodes. As the arc passes through the mercury gas, ultraviolet radiation is produced which is subsequently absorbed by the phosphor coating and re-radiated in the visible region of the electromagnetic spectrum. Phosphor coatings are formulated to produce a desired spectral composition for the generated light. As a result, the luminous efficacies of two lamps with similar energy consumption but different phosphor coatings will vary.

Fluorescent lamp output is also directly related to the vapor pressure of the mercury contained in the lamp. The mercury vapor pressure varies as a function of the lamp's minimum bulb wall temperature, or the coolest spot on the lamp, which causes the mercury to condense resulting in a less-than-optimum mercury vapor pressure. The optimum mercury vapor pressure occurs when the minimum bulb wall temperature is about $40^{\circ} \mathrm{C}$ (Kaufman, 1984) which corresponds to an ambient operating temperature of about $25^{\circ} \mathrm{C}$ (Sylvania, Undated A). Therefore, as the ambient operating temperature varies, the mercury vapor pressure fluctuates resulting in decreased light output.

Fluorescent lamps require a ballast for proper operation. The primary function of the ballast is to limit the current supplied to the lamp and to supply a sufficient starting voltage to the lamp. The ballast may be integral to the lamp assembly, as in self-ballasted lamps, or it may be a separate component as in common tubular and compact fluorescent lamps. In any case, all fluorescent lamps have unique starting and operating characteristics necessitating the need for a variety of ballasts. Because of the dependence of lamps on ballasts, it is only logical that any discussion of fluorescent technology be in terms of lamp/ballast systems rather than individual components. Fluorescent lamp/ballast circuits are typically categorized according to their starting characteristics and include preheat, instant start, and rapid start.

\subsubsection{Preheat}

Preheat circuits, the original fluorescent lamp circuits, are composed of the lamp, ballast and a starter. When the ignition process is started, the starter preheats the electrodes with a limited current. After the electrodes are heated, the starter opens and the ballast applies a voltage across the lamp striking the arc. Preheat circuits typically have the longest delay between ignition and operation.

\subsubsection{Instant Start}

Because the long delay in striking the arc was found to be objectionable, an instant start circuit was developed. Instant start circuits are different in that the cathodes are not heated prior to striking the arc between the cathodes. Rather, the ballast provides a sufficiently large voltage which instantaneously heats the electrodes causing them to emit electrons. The large voltage also overcomes the resistance to striking the arc imposed by the large distance between the electrodes. Instant start circuits have the advantage of providing light immediately but the high starting voltage that permits instantaneous ignition also rapidly degrades the cathodes which decreases lamp life. 


\subsubsection{Rapid Start}

Clearly the starting characteristics of instant start fluorescent lamps are ideal. However, the larger ballasts and decreased lamp life associated with instant start circuits became an issue and thus rapid start lamps were developed. The rapid start ballast eliminates the need for the starter used in the preheat circuit by providing a continuous heating current to the cathodes throughout lamp operation. The cathode heaters also eliminate the high starting voltage needed in the instant start circuit to arouse electrons from a "cold" state because the cathodes are continuously warmed. Similar to preheat circuits, rapid start circuits also experience a delay from ignition to full operation although the delay is much shorter.

\subsubsection{High Intensity Discharge Lamps}

High Intensity Discharge (HID) sources also generate light through a gas discharge process and as such they operate on much the same principle as fluorescent lamps. As gas discharge sources, HID lamps consist of an arc tube enclosed inside a larger glass bulb and require a ballast for operation. The arc tube contains electrodes and fill gases making it nearly identical to a fluorescent lamp with three exceptions: a) the composition of the fill gases varies; b) the gasses are subject to much higher pressures; and, c) the arc tube is much smaller and is not constructed of glass. Since HID sources contain the arc tube inside a larger glass bulb, the arc tube is insulated rendering HID lamp light output much less susceptible to the temperature effects experienced by fluorescent lamps (Kaufman, 1984, p8-45).

In contrast to fluorescent lamps, HID lamps do not immediately produce light once they are turned on. This is a necessary consequence of the lamp's need to generate enough heat to build the vapor pressure inside the arc tube to the level necessary for full light output. The length of the warm-up period is 4-5 minutes for High Pressure Mercury Vapor lamps, 1-2 minutes for Metal Halide lamps, and 3-4 minutes for High Pressure Sodium. Similarly, HID lamps have a restrike time which is the time delay from when the lamp is extinguished until it cools down enough for the arc to be restruck.

\subsubsection{High Pressure Mercury Vapor}

High Pressure Mercury Vapor lamps, or simply Mercury Vapor lamps as they're often called, are the high pressure version of fluorescent lamps. In addition to the general differences noted earlier, primary differences between Mercury Vapor and fluorescent lamps are that the quartz arc tube is not coated on the inside with a phosphor coating; and, the Mercury Vapor lamp contains a starter electrode located adjacent to one of the main electrodes.

The starting process begins when a starting voltage is applied between the main electrodes and between the starter electrode and its adjacent main electrode. The first arc to strike is between the starter electrode and the adjacent main electrode because the close proximity reduces the open circuit resistance to striking the arc. After the starter arc is struck, the mercury inside the arc tube begins to vaporize increasing the pressure until the resistance to striking the main arc is overcome. After the main arc strikes, the starter arc expires and mercury vaporization continues as the temperature inside the arc tube increases. Full light output is realized when the vapor pressure reaches an optimum level (Sylvania, Undated B).

Because the pressure inside the Mercury Vapor arc tube is higher than inside the fluorescent lamp, a large portion of the lamp's light output shifts from the ultraviolet region of the spectrum into the visible region. Consequently, the absolute need for a phosphor coating is negated. However, because clear Mercury Vapor lamps possess poor color rendering qualities, phosphor coatings are often added to the inside of the outer bulb to improve the spectral composition of the light. 
Unfortunately, the improvement is limited. As a result, Mercury Vapor lamps have always been notorious for poor spectral composition resulting in some of the lowest luminous efficacies of gas discharge sources. Therefore, their application in building interiors is very limited.

\subsubsection{Metal Halide}

An improvement on the Mercury Vapor lamp is the Metal Halide lamp. The two are nearly identical in their construction and operation with the exception that iodides such as thorium, scandium and sodium are added to the arc tube (Sylvania, Undated C). The addition of the halides causes the emitted light to have a better spectral composition than mercury vapor light and thus an increase in efficacy is realized.

Metal Halide lamps are somewhat temperamental in their operation, however. The slightest variation in halide content from lamp to lamp can cause the spectral composition of the light to shift, sometimes drastically, resulting in noticeable variations in the color of the lamps.

\subsubsection{High Pressure Sodium}

High Pressure Sodium (HPS) lamps are, again, very similar to Mercury Vapor and Metal Halide lamps in their operation and starting characteristics. Unlike the other HIID lamps however, HPS lamps are constructed with a ceramic arc tube that contains sodium and is much more slender and longer than the quartz tube. Because the slenderness of the tube prevents it from having a starter electrode, the ballast must provide a much larger voltage pulse to start the lamp. As HPS lamps age, the electrodes evaporate and the material is re-deposited on the inside of the ceramic arc tube causing it to darken. At the same time, the sodium leaks through the arc tube and darkens the outer bulb. The darkening of both the ceramic arc tube and the outer bulb cause the lamp operating temperature to rise which in turn causes the lamp operating voltage to increase. In fact, the lamp voltage increases about one volt for every 1000 hours of operation (Murdoch, 1985). The end result is that long before the electrodes completely evaporate, the lamp requires a substantially higher supply voltage than the ballast can produce to strike and maintain the arc.

The sodium content of the gases in the arc tube give the lamp its characteristic orange spectral qualities preventing the lamp from being widely applied to commercial interiors. However, recent research and development efforts are producing lamps with spectral properties more appropriate for indoor use.

\subsection{Ballasts}

Ballasts are electrical devices which provide electrical discharge lamps with proper circuit conditions necessary for operation. Primarily ballasts limit the current available to gas discharge sources and supply a sufficient voltage to strike the lamp's arc. Current limiting is important because gas discharge sources are negative resistance phenomena. This means that, without a current limiting device, the arc will increase its current consumption until the lamp ultimately destroys itself (Sylvania, Undated A). The simplest current limiting device is a resistor placed in series with the lamp. However, because the power losses for resistors are very high, ballasts are a more economical means of controlling lamp voltage and current.

Gas discharge sources appear to be constant sources of light, implying a sustained continuous arc stream. However, a closer inspection reveals that the arc is actually a very rapid series of unsustained arcs. The arcs are struck 100 to 120 times per second corresponding to the crests and troughs of 50 and $60 \mathrm{~Hz}$ ac voltage respectively. While it seems obvious that an ac voltage with a sinusoidal wave form of sufficient magnitude would be appropriate for restriking the lamp, the required starting voltage is of near instantaneous duration. Therefore, the voltage between peaks is 
unnecessary and in fact contributes to ballast losses. To limit these losses and yet maintain the peak voltage requirements, ballasts are designed to superimpose voltage peaks on an otherwise shallower sinusoidal wave form. The degree to which a ballast limits its power losses is described by the voltage crest factor which is the ratio of the peak voltage to the rms voltage where the rms voltage is calculated by dividing the peak voltage by the square-root of two. For the voltage peaks to be beneficial to lamp operation, the ballast ensures they are applied to the lamp electrodes as the magnitude of the fluctuating lamp current passes through zero corresponding to the lamp's expiration.

\subsubsection{Electromagnetic Ballasts}

Electromagnetic ballasts are the oldest of the two types of ballast technology. They are manufactured in either standard or high-efficiency configurations where the major difference between the two is the material used for the coil windings in the transformer. The standard version uses aluminum wire while the high-efficiency electromagnetic ballasts use copper windings. It should be noted that the standard version is no longer manufactured and sold for commercial purposes in the US because its efficiency does not meet federal energy regulations (Piette, Krause \& Verderber, 1989; National Appliance Energy Conservation Amendments, 1988).

\subsubsection{Electronic Ballasts}

Electronic ballasts are more efficient devices showing great promise for future applications. Electronic ballasts electronically convert the $60 \mathrm{~Hz}$ frequency of the input voltage to 20 to $30 \mathrm{kHz}$, or higher, required by the lamps. As a result, the ballasts are much more efficient, and the lamp flicker that is sometimes characteristic of $60 \mathrm{~Hz}$ circuits is virtually eliminated because the arc is struck much more frequently. Additional benefits of electronic ballasts include higher lamp efficacy and lower internal ballast losses.

\subsection{Fixtures}

A fixture is the housing for a lamp and its associated ballast, if one is required. When a lamp(s) is placed into a fixture, the complete assembly is termed a luminaire. Its primary purpose is to control the light distribution of the enclosed lamp(s) and direct the light in a desired direction. As such, fixtures often include an optical system consisting of reflectors and/or lenses. Because a lamp is put into a container of some type, all of the light generated by the enclosed lamp will not leave the fixture. In fact some of the light will get trapped. The percentage of rated bare lamp lumens emitted from the luminaire is described as the luminaire's luminous efficiency. Luminous efficiency is affected by a number of factors including the efficiency of the optical system and the environment in which the luminaire is installed.

The design of the optical system is perhaps the largest determinant of fixture efficiency. Without effective reflectors and lenses, fixtures cannot be expected to deliver the light generated by a lamp to where it is needed. Therefore, because optical efficiency depends upon mechanical manipulation, fixture efficiency is predictable to some extent.

\subsection{Summary}

Although lighting components appear to be relatively simple devices, they are, indeed, as previous descriptions indicate, complex scientific assemblies whose proper operation depends upon a myriad of interacting factors including electrical and environmental conditions. The electrical interaction is important for predicting lamp/ballast compatibility because the two operate as a system. Environmentally, temperature is a critical factor determining lamp output and efficacy for fluorescent lamps. 


\section{Testing Methods and Standards}

In order to specify energy limitations for various technologies, it is helpful to understand how the operating characteristics of lamps, ballasts and luminaires are measured. In most cases, international, regional and national organizations oversee the development of test procedures for measuring these characteristics. At the international level, there are two such organizations: the International Electrotechnical Commission (IEC), and the Commission Internationale de l'Eclairage (CIE). The IEC is responsible for developing standards pertaining to electrical products such as lighting components including lamps and ballasts while the CIE develops recommended procedures for measuring photometric and colorimetric properties of lamps.

At the regional level, the European Committee for Electrotechnical Standardization (CENELEC) has been recognized as the organization whose harmonized standards relating to lighting will apply to the European Communities (EC) and preempt individual member's standards. This does not mean that the Association Française de Normalisation (AFNOR), the British Standards Institution (BSI), and the Deutsches Institut für Normung (DIN), the French, British and German national standards organizations respectively, will cease to exist. Rather, they are required to adopt CENELEC standards and publish them as the minimum national standard which they can supplement with additional requirements. In addition, CENELEC is required to base their standards on IEC standards (Cooke, 1988). It is clear through cross referencing of the various national indices on standards that this chain of events is occurring. For example, in addition to many of the BSI standards being listed as equivalents to CENELEC standards, CENELEC standards are published as IEC standards with only very minor changes. As a consequence of these developments, subsequent discussions regarding testing methods in Europe throughout the remainder of this report will be limited to the IEC documents.

Beyond the European Communities, a number of other national organizations exist. In North America, the Illuminating Engineering Society of North America (IESNA) publishes many documents describing testing methods for the various types of lamps including electrical and photometric properties. The IESNA membership includes Canada, Mexico and the United States. In the individual countries, the Canadian Standards Association is responsible for Canadian standards while the American National Standards Institute (ANSI) is the secretariat for US standards. The Japanese Industrial Standards Committee (JIS) is responsible for publishing Japanese documents. Unlike most of the other countries of the world, the JIS publishes testing methods for both electrical characteristics and photometric properties.

Table 1 provides an overview of the comprehensiveness of several different organization's testing method programs. Particularly, the matrix shows that for older technologies such as fluorescent lamps, mercury vapor lamps and magnetic ballasts, the test procedures are plentiful. However, for more recent technological developments such as electronic ballasts and compact fluorescent, metal halide and high pressure sodium lamps, the standards are sparse. Another observation to be made from the table is that the organizations can generally be categorized as either being interested in either the electrical or the photometric properties of lighting technologies. The organizations primarily interested in photometric properties include the CIE and IES with the remaining organizations interested in electrical properties. As a result, only a very limited number of tests exist for lamp and luminaire photometry. Fortunately, luminaire photometry does not require a vast number of methods for different lamp and ballast combinations because its aim is to quantify the performance of the optical system of the luminaire which is largely independent of lamp and ballast type. A complete list of test methods is included in appendices A and B. Appendix A lists the test methods published by each of the standards organizations while Appendix B provides the same list sorted by the different technologies. 


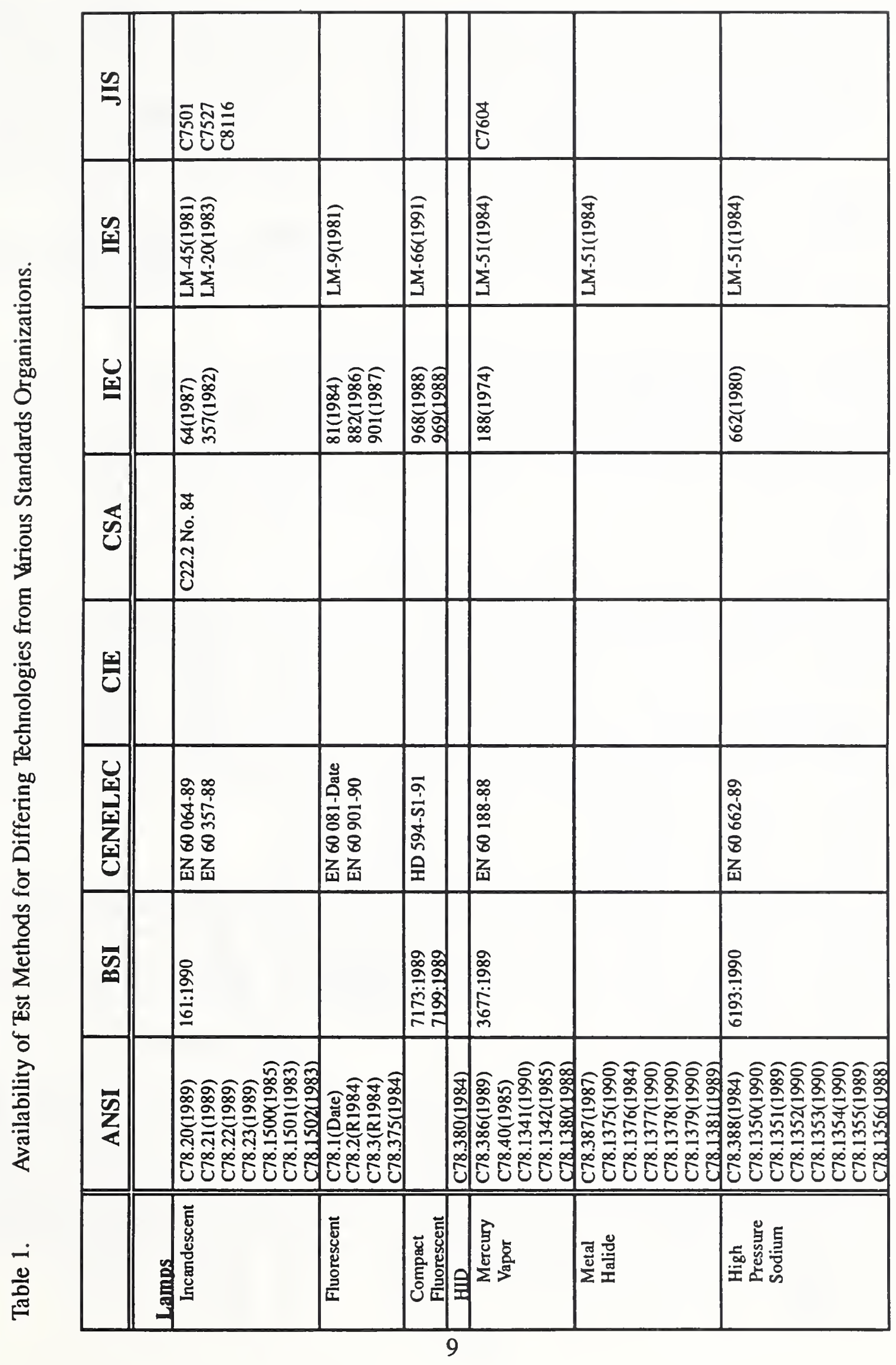




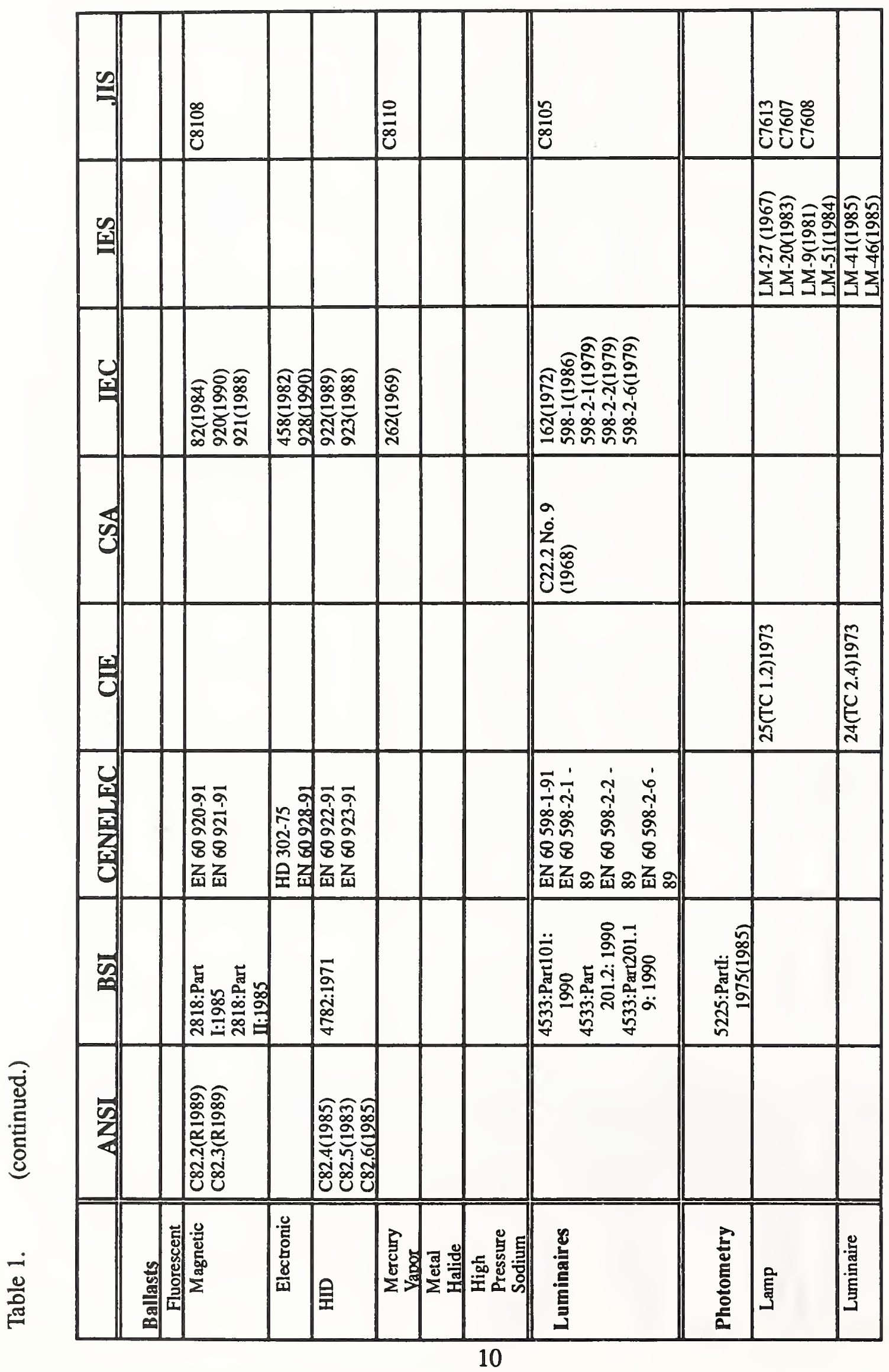


Finally, the review of testing methods shows that these methods provide a common ground which can be used to classify products and ensure that components, regardless of the manufacturer, are compatible based upon the published rated performance data. It must be noted that standards organizations do not establish minimum energy efficiency performance standards. The measurements made according to the testing procedures are only used to classify pieces of equipment. The lone exception to this approach is Canada. Canadian Standards Association documents establish minimum efficiency requirements for specific equipment in addition to describing the testing procedures to be followed for determining compliance.

Since testing methods for each technology are very similar across organizations, the present report describes each particular technology individually. The discussion begins with lamps and is followed by ballasts and luminaires.

\subsection{Lamps}

Lamp testing procedures describe methods for making reproducible measurements of electrical and photometric properties, although all procedures do not address both properties. Generally, ANSI and IEC documents describe electrical testing; IES and JS documents describe both electrical and photometric testing; and, CIE documents describe photometry. Additionally, ANSI, IEC and IES publish separate documents for each type of lamp while there is only one JIS document which describes general tests for all gas discharge sources.

\subsubsection{Electrical measurements}

Two different sets of lamp operating characteristics are of interest to the lighting industry. First are the electrical characteristics which includes voltage and current requirements as well as power consumption. The second set includes photometric or light generating characteristics. Although these two characteristics are closely related, the tests for each are described separately. This is because electrical characteristics generally pertain to component compatibility issues such as whether a lamp can be operated with a particular ballast. The photometric characteristics are usually used in the process of designing a lighting system based on quantity of light generated by a properly operating lamp/ballast system. As a result, our discussion begins with the tests related to electrical characteristics followed by a discussion of photometric characteristics.

\subsubsection{Incandescent}

Incandescent lamps are the most straightforward lamp available and their simplicity is echoed in the standards describing the testing methods. In general, the standards describe performance requirements rather than the measurement methods used to obtain such data since, unlike the situation for fluorescent lamps, the power consumption of incandescent lamps is not sensitive to ambient operating conditions. Typically, the standards require lamps consuming a certain number of watts to produce a given number of lumens.

\subsubsection{Tubular Fluorescent Lamps}

The measurement procedures for tubular fluorescent lamps, including T8 as well as T12 lamps, describe methods for making reproducible measurements of electrical characteristics such as total power consumption, lamp voltage, and the current passing through the arc and cathodes. However, since the operating characteristics of fluorescent lamps are very sensitive to the conditions under which the lamps operate (Kaufman, 1984), standards are careful to provide guidance for controlling these variables. The variables critical to lamp operation are listed in Table 2 with the conditions required by each standard. 
Table 2. Summary of Stipulated Operating Conditions Affecting Tubular Fluorescent Lamp Output.

\begin{tabular}{|c|c|c|c|c|}
\hline & $\begin{array}{l}\text { ANSI } \\
\text { C78.375-1991 }\end{array}$ & $\begin{array}{l}\text { IES } \\
\text { LM-9-1988 }\end{array}$ & $\begin{array}{l}\text { IEC } \\
81-1984\end{array}$ & $\begin{array}{l}\text { JIS } \\
\text { C7801-1988 }\end{array}$ \\
\hline $\begin{array}{l}\text { Proportion of rms Sum of } \\
\text { Harmonics to Fundamental }\end{array}$ & $<3 \%$ & $<3 \%$ & $<3 \%$ & "substantially sinusoidal" \\
\hline Ambient Temperature & $25^{\circ} \mathrm{C} \pm 1{ }^{\circ} \mathrm{C}$ & $25^{\circ} \mathrm{C} \pm 1{ }^{\circ} \mathrm{C}$ & $25^{\circ} \mathrm{C} \pm 1^{\circ} \mathrm{C}$ & $20^{\circ} \mathrm{C} \pm 15^{\circ} \mathrm{C}$ \\
\hline Air Velocity & $1.5 \mathrm{~m} / \mathrm{min}$ & $4.6 \mathrm{~m} / \mathrm{min}$ & $\begin{array}{l}\text { "draught free } \\
\text { environment" }\end{array}$ & $\begin{array}{l}\text { "no influence of } \\
\text { drafts" }\end{array}$ \\
\hline Percent Relative Humidity & 一 & - & $<65$ & $65 \pm 20$ \\
\hline Lamp Posture & Horizontal & - & Horizontal & - \\
\hline Lamp Seasoning & $100 \mathrm{~h}$ & $100 \mathrm{~h}$ & $100 \mathrm{~h}$ & - \\
\hline $\begin{array}{l}\text { Time for Lamp To Reach } \\
\text { Equilibrium Before Test }\end{array}$ & $\geq 15 \mathrm{~min}$ & $\geq 15 \mathrm{~min}$ & - & - \\
\hline $\begin{array}{l}\text { Type of Ballast Used to } \\
\text { Operate Lamp }\end{array}$ & Reference & Reference & Reference & Reference \\
\hline
\end{tabular}


For tubular fluorescent lamps, the most notable difference among the different standards relates to the ambient temperature of the space in which the lamp is tested. Although ANSI, IES, and IEC recognize the extreme sensitivity of fluorescent lamps to ambient operating temperature, the Japanese standard permits an extremely wide operating range. It is well known that fluorescent lamps reach their peak light output at an ambient temperature of about $25^{\circ} \mathrm{C}$ and that light output falls off to approximately 80 percent and 91 percent of maximum output (Sylvania, Undated A) at the respective ambient temperature extremes of $5^{\circ} \mathrm{C}$ and $35^{\circ} \mathrm{C}$ permitted by the Japanese standard.

This wide range of acceptable temperatures is troubling considering that these tests are also used to determine the photometric rating of lamps.

In addition to detailed specifications for the environmental conditions, the fluorescent lamp standards also carefully specify electrical supply characteristics. These include the need to ensure the nearly sinusoidal wave shape of the voltage supply. This is necessary since power supplied directly by utilities is not of uniform quality and lamp operation may be affected if the supply is left uncontrolled. Similarly, the ballast used to operate a fluorescent lamp may influence the lamp's operating characteristics. Thus, to provide a common test basis, standard linear reactor ballasts are used to operate fluorescent lamps during the tests.

Beyond outlining the testing conditions as described above, the standards also provide detailed information for constructing the test set-up and instructions for executing the tests. Specifically, the standards provide circuit diagrams for the different types of lamps including preheat, rapid start and instant start including the placement of metering devices. A careful review of the various test methods reveal these descriptions to be the most consistent among the various standards.

\subsubsection{Self-Ballasted Lamps}

A self-ballasted lamp is defined as "a tubular fluorescent or other discharge lamp unit that incorporates, permanently enclosed, all elements that are necessary for starting and for stable operation, and which does not include any replaceable or interchangeable parts" (IEC 969, 1989). Because these types of lamps are not very common and because component compatibility is not an issue due to their integral construction, the need for testing procedures is not overwhelming. Consequently, ANSI and IEC have the only two published documents. These are summarized in Table 3. An inspection of the operating conditions that can affect lamp output shows nearly identical requirements for the two documents with three exceptions. First, ANSI places no relative humidity requirements on the space nor do they recommend a minimum warm-up time for the lamp before it is tested. Subsequently, the IEC does not stipulate a burning position for the lamp under test.

\subsubsection{Compact Fluorescent}

Compact fluorescent lamps are a cross between tubular fluorescent lamps and self-ballasted lamps in their construction and testing procedures. They are similar to tubular fluorescent lamps in that they require a separate ballast for operation; and, they are similar to self-ballasted lamps in their physical size and construction characteristics such as the U-tube configuration. Again, because compact fluorescent lamps are relatively new to the market, testing procedures are not as readily available as they are for tubular fluorescent lamps. Only the IEC and IES have published test methods. The test requirements are summarized in Table 4.

Although many of the same testing requirements for self-ballasted lamps are also stipulated for compact fluorescent lamps, two observations are worthy of attention: 1) these lamps are operated 
Table 3. Summary of Stipulated Operating Conditions Affecting Self-Ballasted Lamp Output.

\begin{tabular}{|c|c|c|}
\hline & $\begin{array}{l}\text { ANSI } \\
\text { C78.5-1991 }\end{array}$ & $\begin{array}{l}\text { IEC } \\
969-1988\end{array}$ \\
\hline $\begin{array}{l}\text { Proportion of rms sum of } \\
\text { Harmonics to Fundamental }\end{array}$ & $<3 \%$ & $<3 \%$ \\
\hline Ambient Temperature & $25^{\circ} \mathrm{C} \pm 1^{\circ} \mathrm{C}$ & $25^{\circ} \mathrm{C} \pm 1^{\circ} \mathrm{C}$ \\
\hline Air Velocity & draft-free room & $\begin{array}{l}\text { "draught-proof } \\
\text { room" }\end{array}$ \\
\hline Percent Relative Humidity & - & $<65$ \\
\hline Lamp Posture & Base-up & - \\
\hline Lamp Seasoning & $100 \mathrm{~h}$ & $100 \mathrm{~h}$ \\
\hline $\begin{array}{l}\text { Time for Lamp To Reach } \\
\text { Thermal Equilibrium Before Test }\end{array}$ & - & as stated by $\mathrm{mfr}$. \\
\hline
\end{tabular}


Table 4. Summary of Stipulated Operating Conditions Affecting Compact Fluorescent Lamp Output.

\begin{tabular}{|c|c|c|}
\hline & $\begin{array}{l}\text { IES } \\
\text { LM-66-1991 }\end{array}$ & $\begin{array}{l}\text { IEC } \\
901-1989\end{array}$ \\
\hline $\begin{array}{l}\text { Proportion of rms sum of } \\
\text { Harmonics to Fundamental }\end{array}$ & $<3 \%$ & $<3 \%$ \\
\hline Ambient Temperature & $25^{\circ} \mathrm{C} \pm 1^{\circ} \mathrm{C}$ & Under Consideration \\
\hline Air Velocity & $5 \mathrm{~m} / \mathrm{min}$ & "draught-free room" \\
\hline Percent Relative Humidity & - & $<65$ \\
\hline Lamp Posture & Base-up & - \\
\hline Lamp Seasoning & $100 \mathrm{~h}$ & $100 \mathrm{~h}$ \\
\hline $\begin{array}{l}\text { Time for Lamp To Reach } \\
\text { Thermal Equilibrium Before Test }\end{array}$ & $\sim 15 \mathrm{~h}$ & - \\
\hline $\begin{array}{l}\text { Type of Ballast Used to } \\
\text { Operate Lamp }\end{array}$ & Reference & Reference \\
\hline
\end{tabular}


with a reference ballast during the test; and, 2) the warm-up time is greatly increased from about 15 minutes to greater than 15 hours.

While the reference ballast requirement is not unexpected since the lamps and ballast are not part of an integral assembly, the increase in warm-up time is a curiosity. The IES document explains that the twin tube construction of compact fluorescent lamps often includes a cold chamber which may take a while to thermally stabilize. The cold chamber, functionally equivalent to the cold spot, is a location in the lamp that is cooler than the remainder of the lamp and functions to control the light output of the lamp by controlling the mercury vapor pressure. In addition, the IES states it may be beneficial to burn the lamp at a higher ambient temperature to optimize output (IES LM-66, 1991) presumably by manipulating the temperature of the cold chamber. The fact that the IES states it may be beneficial, rather than it is beneficial, hints that because the technology is continuously developing, certain performance characteristics are unknown. Thus, it is difficult to establish requirements for some factors that are thought to be of importance. This is likely the reason the IEC document does not stipulate a warm-up time or a burning posture and states that the ambient operating temperature is under consideration.

Although the IES document provides a general warm-up time for the lamp to reach equilibrium, it is not without a caveat. In fact nearly all lamp testing method documents generally state that the recommended warm-up times are minimums and that lamp power, voltage and current should be sampled roughly every 15 minutes until a change of less than 1 percent is recorded for three successive time periods.

\subsubsection{High Intensity Discharge}

In general, each standardizing organization publishes a document specific to an individual lamp type such as high pressure mercury vapor, metal halide and high pressure sodium. The only organization that publishes a document to cover all three lamps at once is the IES.

\subsection{High Pressure Mercury Vapor}

Perhaps because high pressure mercury vapor lamps are the oldest of the HIID lamps, there are more standards describing test methods. In this case ANSI, IES, IEC and JIS all publish testing procedures. The contents of the various procedures are relatively well harmonized with a few minor exceptions. See Table 5.

The first discrepancy is in the proportion of the rms sum of harmonics to the fundamental. As in previously described Japanese lamp standards, the language pertaining to the sinusoidal wave form of the power source is not as explicit as it is in other organizations' documents and JS C76041985 is no exception. Another discrepancy among the documents is the relatively tight ambient temperature range in the IES method compared to those of other organizations. Finally, there is some disagreement on lamp burning position and warm-up times. The IEC and JS stipulate a base-up burning position while ANSI allows the lamp manufacturer to specify the burning position. As with other discharge lamp test methods, there is also disagreement on the minimum times to equilibrium for the very reason described in the compact fluorescent lamp section discharge lamps are simply unpredictable and the only way to ensure measurements are being made at the appropriate time is to monitor lamp power, voltage and current until they reach equilibrium.

\subsection{Metal Halide}

Testing methods for metal halide lamps, which are limited to North American documents, are summarized in Table 6. As indicated earlier, the IES test method for metal halide lamps is the same 
Table 5. Summary of Stipulated Operating Conditions Affecting High Pressure Mercury Vapor Lamp Output.

\begin{tabular}{|c|c|c|c|c|}
\hline & $\begin{array}{l}\text { ANSI } \\
\text { C78.386-1989 }\end{array}$ & $\begin{array}{l}\text { IES } \\
\text { LM-51-1984 }\end{array}$ & $\begin{array}{l}\text { IEC } \\
188-1974\end{array}$ & $\begin{array}{l}\text { JIS } \\
\text { C7604-1985 }\end{array}$ \\
\hline $\begin{array}{l}\text { Proportion of rms sum of } \\
\text { Harmonics to Fundamental }\end{array}$ & $<3 \%$ & $<3 \%$ & $<3 \%$ & "nearly sinusoidal" \\
\hline Ambient Temperature & $25^{\circ} \mathrm{C} \pm 5^{\circ} \mathrm{C}$ & $25^{\circ} \mathrm{C} \pm 1{ }^{\circ} \mathrm{C}$ & $25^{\circ} \mathrm{C} \pm 5^{\circ} \mathrm{C}$ & $25^{\circ} \mathrm{C} \pm 5^{\circ} \mathrm{C}$ \\
\hline Air Velocity & "draft free" & - & - & - \\
\hline Lamp Posture & per lamp spec. & - & Base-up & Base-up \\
\hline Lamp Seasoning & $100 \mathrm{~h}$ & $100 \mathrm{~h}$ & $100 \mathrm{~h}$ & $100 \mathrm{~h}$ \\
\hline $\begin{array}{l}\text { Time for Lamp To Reach } \\
\text { Thermal Equilibrium Before Test }\end{array}$ & $\geq 15-20 \mathrm{~min}$ & $\geq 10-30 \mathrm{~min}$ & $\begin{array}{l}\text { until electrically } \\
\text { stable }\end{array}$ & - \\
\hline $\begin{array}{l}\text { Type of Ballast Used to } \\
\text { Operate Lamp }\end{array}$ & Reference & Reference & Reference & Reference \\
\hline
\end{tabular}


Table 6. Summary of Stipulated Operating Conditions Affecting Metal Halide Lamp Output.

\begin{tabular}{|c|c|c|}
\hline & $\begin{array}{l}\text { ANSI } \\
\text { C78.387-1987 }\end{array}$ & $\begin{array}{l}\text { IES } \\
\text { LM-51-1984 }\end{array}$ \\
\hline $\begin{array}{l}\text { Proportion of rms sum of } \\
\text { Harmonics to Fundamental }\end{array}$ & $<3 \%$ & $<3 \%$ \\
\hline Ambient Temperature & $25^{\circ} \mathrm{C} \pm 5^{\circ} \mathrm{C}$ & $25^{\circ} \mathrm{C} \pm 1^{\circ} \mathrm{C}$ \\
\hline Air Velocity & "draft free" & - \\
\hline Lamp Posture & per lamp spec. & - \\
\hline Lamp Seasoning & $100 \mathrm{~h}$ & $100 \mathrm{~h}$ \\
\hline $\begin{array}{l}\text { Time for Lamp To Reach } \\
\text { Thermal Equilibrium Before Test }\end{array}$ & $\geq 15-20 \mathrm{~min}$ & $\geq 10-30 \mathrm{~min}$. \\
\hline $\begin{array}{l}\text { Type of Ballast Used to } \\
\text { Operate Lamp }\end{array}$ & Reference & Reference \\
\hline
\end{tabular}


as for high pressure mercury vapor and high pressure sodium lamps. Therefore, the tight ambient temperature range remains as does the disagreement in time to equilibrium. Perhaps more interesting is the lamp posture issue. Metal halide lamps are very sensitive to burning position. This is particularly true when a metal halide lamp is mounted in a horizontal position. In this position, the convection currents inside the arc tube cause the arc to peak in the middle. The fact that arc tube interferes with the peaked arc results in decreased light output. This problem is acknowledged by the ANSI standard but the IES has chosen not to stipulate a burning position. The absence of this requirement could have a profound effect on measured lamp output.

\subsection{High Pressure Sodium}

High pressure sodium lamps have not been very common in offices of the past. However, as their spectral composition improves, they should become increasingly popular because of their high efficacies.

Inspection of the high pressure sodium lamp test methods (see Table 7) reveals nearly identical requirements as for high pressure mercury vapor and metal halide lamps with one lone exception. The warm up time is inconsistent. But as was mentioned earlier, this is not an issue because of the caveat which recommends constant monitoring of lamp power, voltage and current until the lamp reaches equilibrium.

\subsubsection{Photometry}

Photometric tests on lamps are primarily performed to quantify the amount of light, or luminous flux, produced by a lamp. The most reliable method of measuring luminous flux typically involves the use of an integrating sphere.

An integrating sphere is a hollow sphere which has a uniform, diffuse coating on its inner surface. When a light source is placed at the center of the sphere and initially turned on, it directly radiates its light to the surface of the sphere. Then, because of the unique geometry of the sphere, the fact that each sub-surface can "see" every other sub-surface, the light is interreflected until all surfaces are equally illuminated. Thus, the magnitude of the interreflected illuminance (lumens $/ \mathrm{m}^{2}$ ) of the sphere's surface is proportional to the lumen output of the lamp. A calibrated photocell can then be placed in the wall of the sphere and if it is shielded from the direct radiation from the source, the lumen output of the lamp can be determined directly (Kaufman, 1984).

One of the assumptions in lamp photometry, and as we'll see later in luminaire photometry, is that the light source is small enough to be considered a point source. The purpose of this assumption is to facilitate the presentation of the multitude of data generated by the test. To ensure this assumption is met, the "Five-Times Rule" is normally invoked to establish the minimum distance from the light source to the photocell. The Five-Times Rule states that in order for a light source to be considered a point source, the distance from the light source to the photocell must be greater than five times the source's largest dimension.

Photometric test methods are published by the IES, JIS and CIE but not by ANSI and IEC. In the case of the IES, the photometry tests are contained in the same documents as the electrical tests described earlier while the JIS and CIE publish separate documents for photometric test methods. All of the test procedures are nearly identical in their basic requirements although some are more comprehensive than others. As is evident from the summary table, Table 8, the IES documents are the least comprehensive, with the CIE and JIS documents equally comprehensive. 
Table 7. Summary of Stipulated Operating Conditions Affecting High Pressure Sodium Lamp Output.

\begin{tabular}{|c|c|c|c|}
\hline & $\begin{array}{l}\text { ANSI } \\
\text { C78.388-1990 }\end{array}$ & $\begin{array}{l}\text { IES } \\
\text { LM-51-1984 }\end{array}$ & $\begin{array}{l}\text { IEC } \\
662-1980\end{array}$ \\
\hline $\begin{array}{l}\text { Proportion of rms sum of } \\
\text { Harmonics to Fundamental }\end{array}$ & $<3 \%$ & $<3 \%$ & $<3 \%$ \\
\hline Ambient Temperature & $25^{\circ} \mathrm{C} \pm 5^{\circ} \mathrm{C}$ & $25^{\circ} \mathrm{C} \pm 1^{\circ} \mathrm{C}$ & $25^{\circ} \mathrm{C} \pm 5^{\circ} \mathrm{C}$ \\
\hline Air Velocity & "draft free" & - & - \\
\hline Lamp Posture & per lamp spec. & - & - \\
\hline Lamp Seasoning & $100 \mathrm{~h}$ & $100 \mathrm{~h}$ & $100 \mathrm{~h}$ \\
\hline $\begin{array}{l}\text { Time for Lamp To Reach } \\
\text { Thermal Equilibrium Before Test }\end{array}$ & $\geq 1 \mathrm{~h}$ & $\geq 10-30 \mathrm{~min}$ & - \\
\hline $\begin{array}{l}\text { Type of Ballast Used to } \\
\text { Operate Lamp }\end{array}$ & Reference & Reference & Reference \\
\hline
\end{tabular}




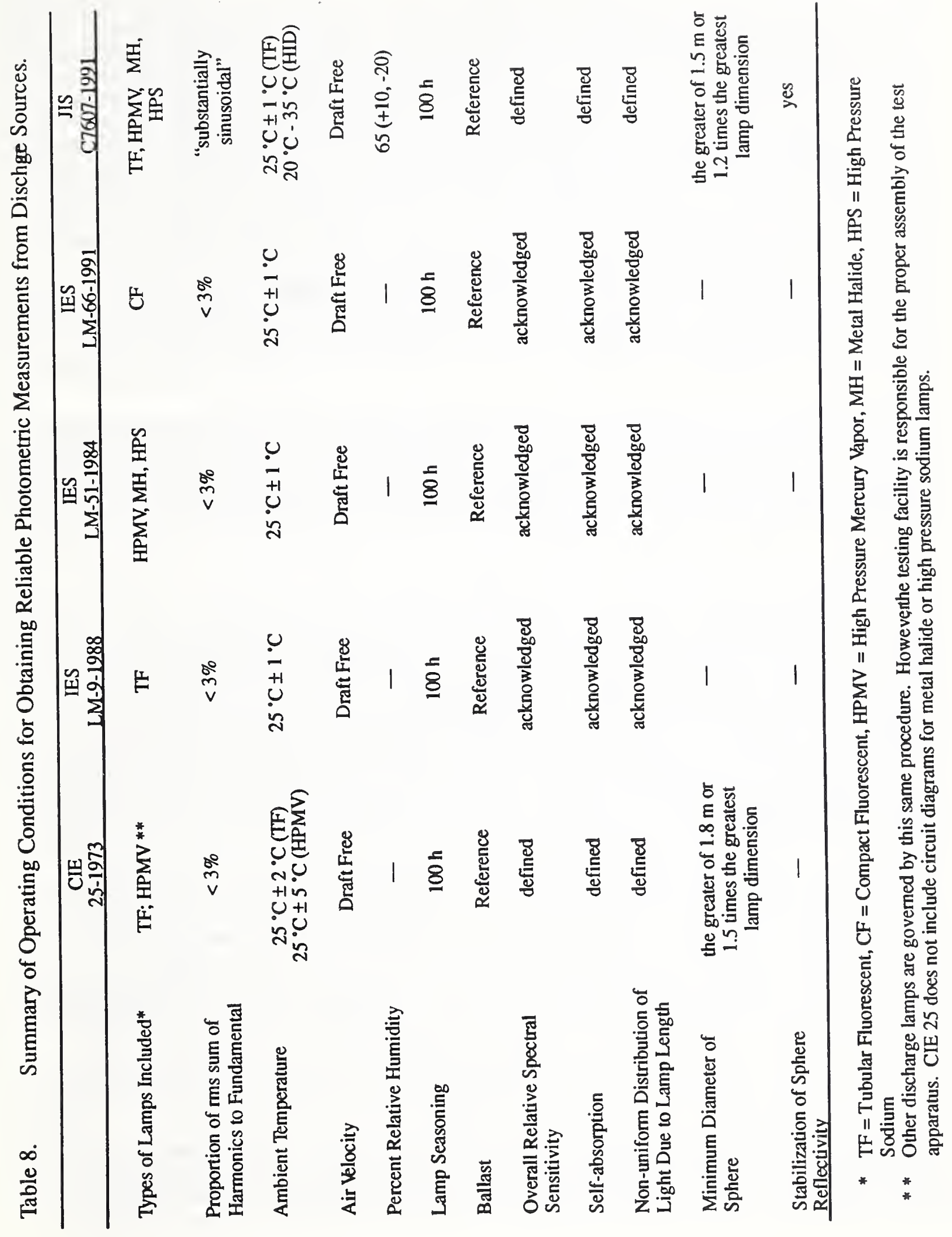


There is a concerted effort by the JIS and CIE documents to emphasize precautions against introducing errors which are not detectable by a watt meter, volt meter, or an ammeter. These include potential errors due to self absorption, the overall spectral sensitivity of the optical assembly and the effect of non-uniform and irregularly shaped light sources. Self absorption refers to the idea that the structural supports of the test lamp may absorb more light than the structural supports of the lamp used to calibrate the sphere initially. Similarly, the overall relative spectral sensitivity of the sphere's optical system will vary if the spectral composition of the test source is different from that of the calibration source. Finally, integrating sphere theory assumes the distribution of light on the interior surface of the sphere by the test lamp is uniform. If this distribution deviates from uniformity, a correction factor is needed. The JIS and CIE documents describe corrective procedures for these potential problems in depth while the IES merely acknowledges these problems may exist. All three documents also emphasize the importance of using precision optical devices in addition to regulating the quality of the power supply. In fact, the language describing the power supply is nearly verbatim from the test methods for lamp performance. Other distinct similarities include the required reference ballast, ambient temperatures and lamp seasoning period.

New requirements above and beyond the electrical requirements required previously for electrical measurements address the physical apparatus. CIE and JIS place minimum dimensions on the diameter of the integrating sphere. This requirement is not mentioned in the IES documents. Also, the Japanese standard requires a lamp similar to the test lamp to be operated inside the sphere for a period of 30 minutes prior to the test lamp being placed in the sphere so as to stabilize the reflectivity of the sphere's interior coating.

\subsection{Ballasts}

All standards organizations use relative comparison methods to measure ballast operation. The comparison is between the performance of reference lamps operating in a circuit containing a reference ballast and the performance of the same lamps operating in a circuit containing a test, or commercial, ballast. This comparison is facilitated by configuring two operating circuits, one containing a reference ballast and the other containing the commercial ballast, such that they are interfaced at a standard lamp. This allows the standard lamp to be operated alternately in the reference ballast and the commercial ballast circuits without being extinguished during the switch over. The measurement procedures require the reference lamp to be electrically stabilized on the reference ballast before any measures are made. The first measures are made for the lamp in the reference ballast circuit. Then, without extinguishing the lamp, the lamp is switched over to the test ballast circuit. The measures for fluorescent lamps are repeated within 30 seconds of the switch over to prevent the commercial ballast from warming-up "in the interest of standardization and reproducible measurements" (ANSI C82.2-1984). For HIID lamps, the measures are taken after the lamp has re-stabilized for at least one to three but less than five minutes (ANSI C82.41985). It is further noted that it is very difficult to switch High Pressure Sodium lamps to a different ballast without extinguishing them. In this case, the test methods make provisions for the lamp to be tested under two different conditions. First, the HPS lamp is tested while it operates with a reference ballast only. Then, the lamp is operated in a two ballast system similar to the system used to test fluorescent, mercury vapor and metal halide lamps except the ballast used to stabilize the lamp is very similar to the test ballast itself. The characteristics measured during the two tests are then used for the normal comparative purposes.

Similar to lamp test methods, all ballast test methods share a few identical requirements. These include the quality of the power supply and the operating environment. In every case, the proportion of the rms sum of the harmonics to the fundamental is limited to 3 percent; and the voltage and frequency are required to be within a small tolerance of the rated values. In addition, 
all ballast test methods require a $25^{\circ} \mathrm{C}$ ambient operating temperature although the tolerance varies slightly from standard to standard. They also state the need to provide for a draft free environment. Any fluctuation in lamp output will affect ballast measurements since the performance of lamps and ballasts are inextricably linked. Evidence for this is the explanation offered in ANSI C82.2-1984 for why the test conditions do not simulate the conditions experienced by the ballast when it is installed in a fixture: "although ballast temperature has an effect on ballast output, these effects are relatively small and a long time is required to arrive at a stabilized ballast condition. Hence, in the interests of uniformity and economy of testing, ballasts are operated in free air and at room temperature" (ANSI C82.2-1984).

\subsubsection{Ballasts for Fluorescent Lamps}

There are two different technologies used to ballast fluorescent lamps: electromagnetic and electronic. Because electromagnetic ballasts are the oldest of the two, there are significantly more documents describing test methods for them than for electronic ballasts.

\subsubsection{Electromagnetic Ballasts}

Earlier in this document the general differences in fluorescent lamp circuitry were described. In particular it was pointed out that preheat and instant start circuits differ from rapid start circuits in that rapid start circuits incorporate cathode heaters while preheat and instant start circuits do not. Cathode heaters provide a continuous low-voltage current to the cathodes which helps facilitate starting and is supplementary to the power consumed by the lamp's arc. The implications of this supplemental power consumption are revealed in the testing procedures.

The test procedures for preheat and instant start lamps make the assumption that the light output of a lamp is linearly related to the power supplied by the ballast. As a result, preheat and instant start ballasts are evaluated based on the relative power they provide to a lamp compared to the power supplied by a reference ballast. For preheat and instant start lamps these measures are easily made. However, for rapid start lamps, the issue of measuring the power supplied to a lamp is more complicated because some of the power is consumed by the cathode heaters. Since it is difficult to isolate the power consumed by the cathode heaters from the power consumed by the arc, ballast output is evaluated based on relative light output. Relative light output is defined as the amount of luminous flux generated by a lamp operating with a test ballast compared to the luminous flux generated by the same lamp operating with a reference ballast. The relative light output is a unitless value called the Ballast Factor and is used to describe the efficiency with which a rapid start circuit produces light.

Nonetheless, Ballast Factors are not a wholly sufficient descriptor of a ballast's efficient use of energy. For example, a ballast's Ballast Factor and its power consumption are largely unrelated. It is possible that as a ballast's Ballast Factor increases, intuitively indicating a more efficient use of energy, the actual power consumption, may also increase. Similarly, a ballast with a slightly lower Ballast Factor may have a lower power consumption. Therefore, the need to quantify the tradeoff between Ballast Factor and power consumption became apparent and the Ballast Efficiency Factor was created.

The Ballast Efficiency Factor (BEF) is a ratio of the Ballast Factor to the power input to the ballast. In this way the efficiencies of all ballasts intended to operate a particular type of lamp can be compared. Note that Ballast Factors were originally defined for rapid start circuits and that because light output of preheat and instant start circuits is not measured in the test procedures, preheat and instant start ballasts do not have Ballast Factors. However, since the preheat and instant start test procedures assume that the power supplied to a lamp is linearly related to light output, Ballast 
Efficiency Factors can also be interpreted for preheat and instant start circuits based on the relative power output of the ballast compared to a reference ballast.

There are two different classifications of electromagnetic ballasts, those with and without cathode heaters, based on the type of lamp with which they are intended to operate: rapid start or preheat and instant start respectively. Therefore, because of the cathode heaters, two different test procedures are used to measure the operating characteristics of the two types of ballasts. However, because both procedures have many requirements in common, both test methods are summarized in Table 9 for ease of comparison.

Four standards organizations have test methods for electromagnetic ballasts including ANSI, CSA, IEC and JS. However, unlike the other organizations who only publish the test methods, the Canadian document approaches testing from a different angle. CSA has developed a test method based on ANSI standards but extended it to determining the efficiency of a particular group of fluorescent lamp ballasts. As a result, the CSA document CAN/CSA-C654-M91 does not stop at measuring the intermediate values of relative light output for rapid start lamps and relative lamp power for instant start lamps. Rather, these values are used to calculate the Ballast Efficacy Factor $^{1}$ data which are published in the document. Because the Ballast Efficiency Factors are similar to the data contained in the US National Appliance Energy Conservation Amendments of 1988, a regulatory document discussed later, only the test requirements of CAN/CSA-C654-M91 will be included here. The stipulated Canadian Ballast Efficacy Factors will be included in the regulatory section for a more direct comparison.

As indicated earlier, there are separate test procedures for ballasts with and without cathode heaters. For preheat and instant start ballasts, ballasts without cathode heaters, the operating characteristics of interest are the power and current delivered to the reference lamps. The power delivered by the test ballast must be greater than 92.5 percent of that delivered by the reference ballast while the delivered current may not be more than 115 percent of that delivered by the reference ballast. These requirements are identical in each standard.

In contrast, the performance of rapid start ballasts is characterized on the basis of the light output and lamp current. Specifically, the light produced by standard lamps operating on the test ballast may generally not be less than 90 percent of the output produced by the same lamps on a reference ballast. Output is measured by locating a photocell with its face normal to the lamp surface and at a distance of $0.13 \mathrm{~m}$ so that its field of view includes the center of the lamp. In addition baffling is employed to minimize the inter-reflections of extraneous light. The current flowing through the reference lamp operating on the test ballast may not be more than 115 percent of the current produced by the reference ballast. Again, these requirements are standard across organizations with one exception: JIS considers the luminous ratio output to equal the ratio of output power.

\subsubsection{Electronic Ballasts}

An alternative to electromagnetic ballasts for fluorescent lamps is electronic ballasts. It was discovered that if fluorescent lamps are operated at much higher frequencies, such as 20 to $30 \mathrm{kHz}$, they become more efficacious and consume less energy. The device capable of operating fluorescent lamps at the higher frequencies is the electronic ballast. Because this is relatively new to the market, only one standard, IEC 929-1990, exists to describe test methods for it. Because

1 Ballast Efficacy Factor as defined in CAN/CSA-C654-M91 is numerically equivalent to the Ballast Efficiency Factor defined in the US National Appliance Energy Conservation Amendments of 1988, 42 U.S.C. § 6201(a). Therefore, this document will use the words efficacy and efficiency interchangeably with respect to ballasts. 
Table 9. Summary of Operating Conditions for Obtaining Reliable Performance Measures from Electromagnetic Ballasts for Fluorescent Lamps.

\begin{tabular}{|c|c|c|c|c|}
\hline & $\begin{array}{l}\text { ANSI } \\
\text { C82.1-1984 }\end{array}$ & $\begin{array}{l}\text { CAN/CSA } \\
\text { C654-M91 }\end{array}$ & $\begin{array}{l}\text { IEC } \\
921-1988\end{array}$ & $\begin{array}{l}\text { JIS } \\
\text { C8108-1983 }\end{array}$ \\
\hline Ambient Temperature & $25^{\circ} \mathrm{C} \pm 1^{\circ} \mathrm{C}$ & $25^{\circ} \mathrm{C} \pm 1^{\circ} \mathrm{C}$ & $25^{\circ} \mathrm{C} \pm 2^{\circ} \mathrm{C}$ & $25^{\circ} \mathrm{C} \pm 1^{\circ} \mathrm{C}$ \\
\hline Air Velocity & Draft Free & $<1.5 \mathrm{~m} / \mathrm{min}$ & Draft Free & Draft Free \\
\hline \multicolumn{5}{|l|}{ Preheat and } \\
\hline $\begin{array}{l}\text { Percentage of Reference Ballast } \\
\text { Power Delivered by } \\
\text { Test Ballast }\end{array}$ & $\geq 92.5$ & $*$ & $\geq 92.5$ & $\geq 92.5$ \\
\hline $\begin{array}{l}\text { Percentage of Reference Ballast } \\
\text { Lamp Current Delivered } \\
\text { by Test Ballast }\end{array}$ & $\begin{array}{l}\leq 115(\mathrm{PH}) \\
\leq 120(\mathrm{RS})\end{array}$ & $*$ & $\leq 115$ & $\leq 115$ \\
\hline \multicolumn{5}{|l|}{ Rapid Start } \\
\hline $\begin{array}{l}\text { Percentage of Reference Ballast } \\
\text { Lamp Current Delivered } \\
\text { by Test Ballast }\end{array}$ & $\leq 115$ & $*$ & $\leq 115$ & $\leq 115$ \\
\hline $\begin{array}{l}\text { Flux }(\Phi) \text { Produced by Lamp } \\
\text { on Test Ballast : Flux } \\
\text { Produced by Lamp on } \\
\text { Reference Ballast }\end{array}$ & $0.90 \leq \Phi \leq 1.0^{\dagger}$ & * & $\geq 90 \%$ & $\mathrm{NA}$ \\
\hline $\begin{array}{l}\text { Percentage of Reference Ballast } \\
\text { Power Delivered by } \\
\text { Test Ballast }\end{array}$ & NA & $*$ & NA & $\geq 90$ \\
\hline Reference Ballast & Series Reactor & $\begin{array}{l}\text { Fixed- or Adj.- } \\
\text { Impedance }\end{array}$ & Series Reactor & Series Reactor \\
\hline $\begin{array}{l}\text { Minimum Power-Factor } \\
\text { for High Power Factor Ballasts }\end{array}$ & .90 & .90 & .85 & .85 \\
\hline
\end{tabular}

* See text for clarification of missing values.

$\dagger-10$ percent is the maximum tolerance permitted for any of the fluorescent lamps listed in ANSI C82.1. The specific tolerance value is specific to lamp type and it may be as low as -5 percent. 
many of the operating characteristics are still unknown, much like compact fluorescent lamps, many of the procedures are not yet specified.

As does the electromagnetic ballast standard, the electronic ballast standard establishes a draft-free ambient test temperature of $25^{\circ} \mathrm{C} \pm 2{ }^{\circ} \mathrm{C}$. The basis of comparison between test and reference ballast, although tentative, is also similar. For example, the standard states that if the ratio of the flux produced by a lamp operated on a test ballast is less than 90 percent of that produced by a lamp on a reference ballast, evidence must be provided proving that the lamp performance is not impaired by the ballast. Although suggestions for types of evidence are not given, the standard does indicate that a relevant test is under development.

Similarly, the total circuit power with the test ballast is specified to be less than 110 percent the power of the circuit with a reference ballast. The current delivered by the test ballast circuit must also be less than 115 percent of the current delivered by the reference ballast circuit. These requirements will eventually be supplemented with requirements for dimming capacity which are now being considered.

The last consideration in the electronic ballast standard relates to the reference ballast. Since lamps operate at a much higher frequency on electronic ballasts than on electromagnetic core-coil ballasts, the usual series-reactor-type reference ballast is no longer appropriate. This is because seriesreactor reference ballasts sometimes alter the 50 or $60 \mathrm{~Hz}$ frequency of the power supply and this transformation would introduce a degree of error in the measurement. Therefore, the reference ballast for electronic ballast testing is a simple resistor which does not distort the frequency of the power supply and is not sensitive to parasitic capacitance.

\subsubsection{High Intensity Discharge Ballasts}

The test methods for HID ballasts which are summarized in Table 10 reflect the same requirements as the test methods for fluorescent lamp ballasts. Although the differences among the test standards are minimal and limited to slightly variable tolerances, there are a few points worth noting. One is the absence of ballast requirements for metal halide lamps in the IEC and JIS documents as well as the lack of a JIS high pressure sodium ballast test. The IEC states that metal halide requirements are under consideration while JIS doesn't even acknowledge the existence of metal halide or HPS lamps. Possible explanations for these absences include the relatively recent appearance of these technologies on the market compared to the amount of time needed to generate a standard, especially in view of the temperamental operation of metal halide lamps.

\subsection{Luminaires}

Of the standards organizations considered in this report, only the IES publishes test methods for obtaining reproducible photometric measurements of luminaires. IES LM-41-1985 describes the testing procedures for indoor fluorescent luminaires while IES LM-46-1985 specifies test methods for indoor luminaires using HID or incandescent lamps. The fluorescent document is the more comprehensive of the two, taking care to specify all of the test requirements.

To begin, the fluorescent document explains that components should be those supplied by the manufacturer rather than reference standards so the luminaire's photometric properties can be characterized under conditions likely to be found in the field. However, in a departure from that intention, it specifies the same electrical supply characteristics stipulated in the previous lamp and ballast test methods. It is reasonable to assume this combination is seen as a good compromise between the desire to characterize the "real" performance of the luminaire and the need to control some conditions for reliability purposes. 
Table 10. High Intensity Discharge Ballasts.

\begin{tabular}{|c|c|c|c|}
\hline & $\begin{array}{l}\text { ANSI } \\
\text { C82.4-1985 }\end{array}$ & $\begin{array}{l}\text { IEC } \\
923-1989\end{array}$ & $\begin{array}{l}\text { JIS } \\
\text { C8110-1987 }\end{array}$ \\
\hline Ambient Temperature & $25^{\circ} \mathrm{C} \pm 5^{\circ} \mathrm{C}$ & $25^{\circ} \mathrm{C} \pm 2{ }^{\circ} \mathrm{C}$ & $25^{\circ} \mathrm{C} \pm 5^{\circ} \mathrm{C}$ \\
\hline Air Velocity & Draft Free & Draft Free & $\begin{array}{l}\text { Virtually Still } \\
\text { Air }\end{array}$ \\
\hline \multicolumn{4}{|l|}{ High Pressure Mercury Vapor } \\
\hline $\begin{array}{l}\text { Percentage of Reference Ballast } \\
\text { Lamp Operating Power (W) } \\
\text { Delivered by Test Ballast }\end{array}$ & $92.5 \leq W \leq 107.5$ & $92.5 \leq W \leq 107.5$ & $92.5 \leq W \leq 107.5$ \\
\hline $\begin{array}{l}\text { Percentage of Reference Ballast } \\
\text { Lamp Current (I) Delivered } \\
\text { by Test Ballast }\end{array}$ & $\mathrm{I} \leq 110.0$ & $\mathrm{I} \leq 115$ & $\mathrm{I} \leq 110$ \\
\hline \multicolumn{4}{|l|}{ Metal Halide } \\
\hline $\begin{array}{l}\text { Percentage of Reference Ballast } \\
\text { Lamp Operating Power (W) } \\
\text { Delivered by Test Ballast }\end{array}$ & $95.0 \leq W \leq 105.0$ & $\begin{array}{l}\text { Under } \\
\text { Consideration }\end{array}$ & NA \\
\hline $\begin{array}{l}\text { Percentage of Reference Ballast } \\
\text { Lamp Current (I) Delivered } \\
\text { by Test Ballast }\end{array}$ & $\mathrm{I} \leq 110.0$ & $\begin{array}{l}\text { Under } \\
\text { Consideration }\end{array}$ & NA \\
\hline \multicolumn{4}{|l|}{ High Pressure Sodium } \\
\hline $\begin{array}{l}\text { Percentage of Reference Ballast } \\
\text { Lamp Operating Power (W) } \\
\text { Delivered by Test Ballast }\end{array}$ & $92.5 \leq W \leq 107.5$ & $92.5 \leq W \leq 107.5$ & NA \\
\hline $\begin{array}{l}\text { Percentage of Reference Ballast } \\
\text { Lamp Current (I) Delivered } \\
\text { by Test Ballast }\end{array}$ & $\mathrm{I} \leq 110.0$ & $\mathrm{I} \leq 107.5$ & NA \\
\hline Reference Ballast & $\begin{array}{l}\text { Fixed- or Variable- } \\
\text { Impedance }\end{array}$ & $\begin{array}{l}\text { Fixed- or Variable- } \\
\text { Impedance }\end{array}$ & $\begin{array}{l}\text { Fixed- or Variable- } \\
\text { Impedance }\end{array}$ \\
\hline $\begin{array}{l}\text { Minimum Power-Factor } \\
\text { for High Power Factor Ballasts }\end{array}$ & .90 & .85 & .85 \\
\hline
\end{tabular}


Measurement conditions are also specified, including an ambient temperature of $25^{\circ} \mathrm{C} \pm 1{ }^{\circ} \mathrm{C}$ in a draft free environment. Further, the standard allows for the control of extraneous light and a proper warm-up period for the lamps to stabilize.

The apparatus used to determine the light distribution characteristics of a luminaire is a movingmirror photometer, or goniometer. It most often consists of a harness which holds the luminaire in its typical orientation and at the center of rotation of a large mirror. The mirror swings through a $180^{\circ}$ or $360^{\circ}$ arc around the central axis of the luminaire and reflects the light directed by the luminaire at a given angle to the photo-detector. The photo-detector records the amount of light as an intensity value. Alternative methods involve a fixed sensor and a rotating luminaire, or a fixed luminaire and a rotating sensor.

The actual procedure for determining the light distribution of a luminaire is commonly known as relative photometry. It involves placing bare lamps in the photometer and measuring their actual photometric distribution from which an approximation of the quantity of light they are producing can be calculated. A normalizing factor is computed comparing the approximated actual lamp output to the published rated output assuming the lamps are operating at rated output. This normalizing factor is then used to correct the distribution values measured for the luminaire when the luminaire, equipped with the identical lamps and ballast used in the bare lamp test, is placed in the harness. The resulting data includes a series of luminous intensity (candlepower) distribution curves for the luminaire, a luminaire luminous efficiency value which is the ratio of luminaire light output to bare lamp output, and coefficients of utilization. Coefficients of utilization (CUs) describe the portion of the initial bare lamp lumens that ultimately reach the task or work plane. Thus, they are dependent upon the geometry and surface reflectances of the room in which the luminaires are installed. CUs are used in the lumen method of lighting analysis to predict how much light will fall on a task surface.

In addition, the document suggests the "Five-Times Rule" for establishing the minimum distance from the luminaire to the photocell. The Five-Times Rule states that in order for a luminaire to be considered a point source, which is necessary for further calculations, the luminaire may not be closer than five times the largest dimension of the largest luminous area to the photocell. In most cases, the largest dimension is along the diagonal of a rectangular luminaire. (This means that a luminaire with a $1 \mathrm{~m}$ diagonal must be at least $5 \mathrm{~m}$ from the photocell.)

Another characteristic of the indoor fluorescent photometry document is its thoroughness as a troubleshooting guide. It points out many potential measurement problems and, unlike any other standard, offers corrective solutions.

\section{IES approved Method for Photometric Testing of Indoor Luminaires Using High Intensity} Discharge or Incandescent Filament Lamps, IES LM-46-1985, provides the same procedural requirements as the fluorescent document, IES LM-41-1985, with but one notable exception. The tolerance of the ambient temperature is the same as the HID lamp and ballast standards' requirement of $25^{\circ} \mathrm{C} \pm 5^{\circ} \mathrm{C}$.

\subsection{Summary and Discussion}

Standardized test procedures outline measurement procedures whereby any laboratory can consistently and reliably rate the electrical and photometric characteristics of lighting equipment. Rated values are then used for one of two purposes: comparing components for compatibility or for designing lighting systems. The following discussion considers the test methods from both perspectives and suggests that there is room for improvement in the procedures depending upon the use of the resulting data. 
First, if the data is to be used for determining component compatibility, the test methods are sound in their structure and the resulting rated values should be reliable and consistent. In fact, the standards from the numerous organizations are remarkably well harmonized with the exception of a few minor inconsistencies. These include variable tolerances for ambient testing temperatures and definitions of "draft free" environments. These differences, however, should not prevent reasonably accurate measurements from being made which will permit reliable assessments of component compatibility.

In contrast, if the rated values are to be used for designing lighting systems, the test methods are not as comprehensive as they should be. For example, recall that the tests are executed under very specific environmental and electrical conditions including specific ambient temperatures, supply voltages, supply voltage wave forms and specific auxiliary equipment such as standard reference ballasts and lamps. Unfortunately, these are not conditions under which the components ultimately operate after being installed in a building. Therefore, the question needs to be asked: "What is the impact of the different operating conditions on component/system performance?" Treado and Collins (1991) evaluated the ANSI test methods with this question in mind and concluded that the ratings determined according to the test procedures do not accurately predict the performance of lighting components in an actual installation because the myriad of thermal and electrical interactions is not adequately addressed.

To begin, Treado and Collins (1991) point out that lighting components are required to operate in thermal environments that are very different from the environments in which they were rated. In contrast to actual installations where lamps and ballasts are typically enclosed in a luminaire that naturally restricts heat dissipation, lamps and ballasts are tested in free air and at a temperature of $25^{\circ} \mathrm{C}\left(77^{\circ} \mathrm{F}\right)$, much less than the temperatures found inside a luminaire. Since it is well known that fluorescent lamp output varies significantly with fluctuations in temperature, the actual fluorescent lamp light output will be different from the rated value. Furthermore, the actual difference in output is difficult to quantify for an actual installation because a building's thermal environment is constantly changing (Treado \& Bean, 1992).

Luminaires are also susceptible to inadequacies in accounting for the thermal environment. First, recall that luminaire photometry requires the bare lamps used in the test to be calibrated at an ambient temperature of $25^{\circ} \mathrm{C}$. Then, the lamps are placed in the luminaire and the luminaire is tested at $25^{\circ} \mathrm{C}$, a temperature less than those commonly found in building plenums (Treado \& Bean, 1992). Consequently, the resulting photometric data does not account for the thermal effects of the plenum.

Yet another restriction in determining the performance of lighting equipment installed in buildings is the use of reference equipment in rating individual components. Fluorescent lamps, for example, are rated when they are operated with a standardized reference ballast. As a consequence, the lamp ratings only reflect the precise electrical interaction permitted by the standard reference ballast. Similarly, commercial ballasts are rated in comparison to a standard reference ballast and standard reference lamps. Because the test methods require the lamps to stabilize on the reference ballast rather than the commercial ballast, the performance characteristics of the commercial ballast operating at thermal and electrical equilibrium with any lamps other than the reference lamps remain unknown.

Clearly, it is possible to accurately predict the performance of lighting components under very specific operating conditions and component combinations. Unfortunately, none of the operating conditions and component combinations used to rate components occur in systems installed in buildings. Thus, it is nearly impossible to make accurate assessments of system performance based on currently available data. 


\section{Regulatory Efforts}

In the early 1970s, the American Society of Heating, Refrigerating and Air-conditioning Engineers, developed Standard 90, one of the first model energy conservation codes. First published in 1975 as Standard 90-75, "Energy Conservation in New Building Design," subsequent revisions were co-sponsored by the Illuminating Engineering Society of North America (IES). The 1980 edition received ANSI status and was published as ANSI/ASHRAE/IES Standard 90A-1980. Since then, it has been revised to its current form, ASHRAE/IES 90.1-1989 "Energy Efficient Design of New Buildings Except New Low-Rise Residential Buildings" although this version has not yet received ANSI approval.

Concurrent with the ASHRAE/IES effort, other building code authorities began developing energy conservation codes using Standard 90 as the technical model. Since the late 70s and early 80s, each of the fifty states has adopted one of these codes (ASHRAE, 1989). The efforts to further develop legislation at the federal and state level continues, however. The Canadian and US Federal Governments have begun appliance rating programs which include regulating the energy consumption characteristics of lighting components while states such as California, New York, and Massachusetts have enacted legislation promoting the responsible use of energy.

Table 11 provides an overview of the pertinence of these regulatory documents to the various lighting technologies. Upon first inspection, the matrix appears to be fairly sparse with different regulations applying in different jurisdictions. However, the regulatory process is in its infancy and as US federal requirements become established, they will become part of state energy codes which will make the matrix more uniform and complete. For example, the state and ASHRAE codes include the federal ballast regulations but not the more recently enacted fluorescent and incandescent lamp requirements. Also note the different approaches to regulating energy efficiency that have developed. The US federal government has decided that an individual component approach is more appropriate while the majority of states and ASHRAE have taken a system design approach.

This section describes ASHRAE/IES Standard 90; the California, Massachusetts and New York legislation; the Canadian Energy Efficiency Act; and, the US Federal Legislation as it pertains to lighting equipment and design of lighting systems. The reader is cautioned, however, that the summaries provided in this report should not be interpreted as definitive interpretations of the respective codes. Rather, every effort has been made to provide information that is applicable to most commercial buildings and minimize discussion of the multitude of exceptions with which each code is riddled. The reader interested in minuscule details is encouraged to consult the individual codes.

\subsection{Canadian Energy Efficiency Act}

The Canadian government has instituted a federal Green Plan to address the effects of energy use on the environment. As part of this Plan, Energy, Mines and Resources Canada (EMR) is administering an Efficiency and Alternative Energy Program including an Energy Efficiency Equipment Program. The Energy Efficiency Equipment Program seeks to reduce emissions into the atmosphere by reducing energy use. To meet this goal, the Energy Efficiency Act will require energy-using products to meet minimum efficiency standards. In addition, some of those products will be required to bear EnerGuide labels similar to US EnergyGuide labels so that consumers will be able to make meaningful product comparisons before making a purchase.

The Energy Efficient Equipment Program intends to establish minimum energy efficiency standards by harmonizing standards with other international trading partners. This is seen as a minimally burdensome approach because if an imported component or system meets the minimum 


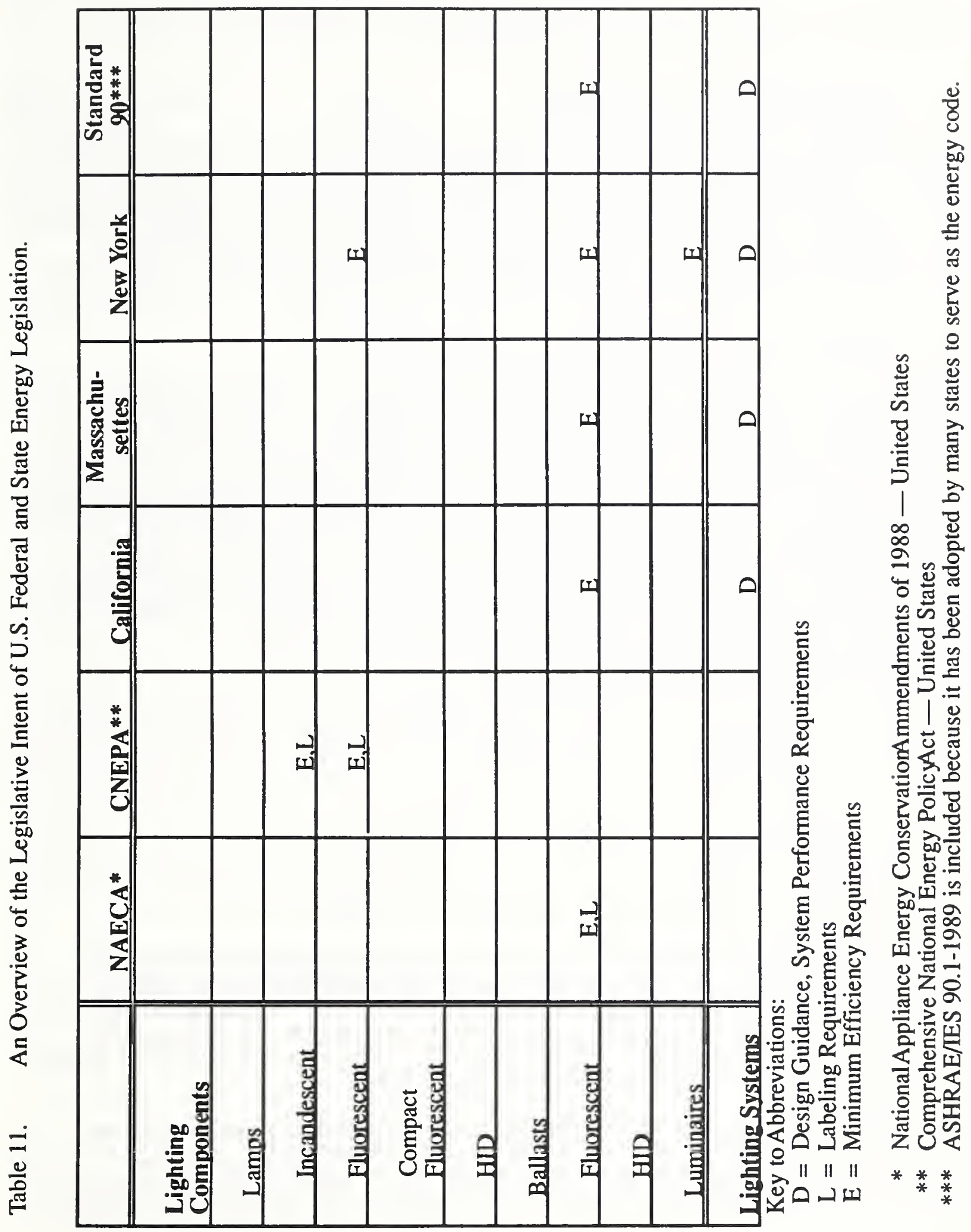


efficiencies of the country of origin, it will already be largely in compliance with Canadian standards (Energy, Mines and Resources Canada, 1992).

\subsection{US Federal Lighting Equipment Legislation}

The United States is currently enacting a comprehensive energy efficiency and labeling program. The goals of the program are to establish minimum efficiencies for energy consuming products and to develop a labeling technique that will allow consumers to make educated buying decisions with respect to energy consumption. The first group of lighting equipment to be regulated was ballasts as part of the National Appliance Energy Conservation Amendments of 1988. Subsequently, fluorescent and incandescent lamps were targeted by the Comprehensive National Energy Policy Act of 1992. Further legislation will address HID lamps as well as luminaires.

\subsubsection{National Appliance Energy Conservation Amendments of 1988}

Public Law 100-357, the National Appliance Energy Conservation Amendments of 1988, is an amendment to the United States Energy Policy and Conservation Act. The amendment serves to limit the energy consumption of fluorescent lamp ballasts. Specifically, it establishes minimum Ballast Efficiency Factors for electromagnetic ballasts designed to be operated with lamps of given characteristics. Ballasts subject to minimum BEFs are those intended for operation with lamps (a) operating at 120 or 277 volts with a $60 \mathrm{~Hz}$ input frequency; (b) having a maximum lamp operating current less than 1000 milliamperes; and, (c) having a starting temperature greater than $-18^{\circ} \mathrm{C}$. In addition, the ballasts must be designed to operate with one of the following lamp configurations: 1) one or two nominal F40T12 40 W rapid start lamps; 2)two nominal F96T12 $75 \mathrm{~W}$ slimline lamps; or, 3) two nominal F96T12HO $110 \mathrm{~W}$ high-output rapid start lamps. The legislation also requires each of the specified ballasts to have a power factor of at least 0.90 .

The Ballast Efficiency Factor, BEF, is determined as

$$
\mathrm{BEF}=\frac{\mathrm{BF}}{\text { Input Power }}
$$

where

$$
\mathrm{BF}=\text { Ballast Factor expressed as a percent less than } 100
$$

Input Power $=$ total wattage of the lamp/ballast combination

and both are determined in accordance with ANSI C82.2-1984. The minimum BEFs for the previously described lamps are shown in Table 12. In addition, Table 12 lists the minimum Canadian Ballast Efficacy Factors stipulated in CAN/CSA-C654-M91. The Canadian standard is nearly identical to the US legislation with the exception of a few additions. The additions are italicized in the table. Note that the additions are for a $347 \mathrm{~V}$ circuit as well as two F32T8 lamps. Further, certain BEFs are applicable to other lamp types as noted.

Ballasts for use in the US that do not meet the US operating requirements or are intended for dimming are not subject to minimum BEFs and are therefore unrestricted in use. Ballasts complying with these standards are required to bear a label with a capital ' $E$ ' enclosed in a circle as an indication of compliance. These requirements do not apply to low-rise residential structures. 
Table 12. US and Canadian Minimum Ballast Performance Requirements*.

Ballasts Designed For the Operation of

One F40T12 lamp $\dagger$

120
277
$347 V$

Two F40T12 lamps $\dagger$

$$
\begin{gathered}
120 \\
277 \\
347 \mathrm{~V}
\end{gathered}
$$

Two F96T12 lamps $\ddagger$

$$
\begin{gathered}
120 \\
277 \\
347 \mathrm{~V}
\end{gathered}
$$

Two F96T12HO lamps§

120
277
$347 \mathrm{~V}$

Two F32T8 lamps

120
277
$347 \mathrm{~V}$

Total Nominal
Lamp Watts

40

40

40

80

80

80

150

150

150

$220 / 226$
$220 / 226$
226

64

64

64
Ballast Efficiency

Factor

1.805

1.805

1.750

1.060

1.050

1.020

0.570

0.570

0.560

0.390

0.390

0.380

1.250

1.230

1.200

* US standards are not as comprehensive as Canadian standards. Therefore, while the entire table applies to Canadian ballasts, only those unitalicized values pertain to the US.

+ Also for use on 34W/48T12/RS and 40W/48T10/RS

\# Also for use on 60W/96T12/IS lamps

$\S$ Also for use on 95W/96T12/HO lamps. 


\subsubsection{Comprehensive National Energy Policy Act}

The Comprehensive National Energy Policy Act, enacted in 1992, outlines energy conservation requirements for fluorescent and incandescent lamps. The use of general service fluorescent lamps, commonly found in office environments, is limited to 4-foot medium bi-pin and 2-foot Ushaped lamps with a rated wattage of 28 or more, as well as 8-foot high output (nominal 0.800 amps) and 8-foot slimline lamps (rated wattage of 52 or more) unless the lamps have a Color Rendering Index (CRI) greater than 81 . The minimum CRIs and luminous efficacies are shown in Table 13. Note that these requirements effectively prohibit the use of any non-tri-phosphor fluorescent lamp.

The minimum luminous efficacy requirements for general service incandescent lamps are limited to reflector lamps with $R$ and PAR bulb shapes but not ER and BR. Further, the lamps must have E26 medium screw bases, a rated voltage or voltage range that is at least partially included in a 115 to 130 volt tolerance, a bulb diameter greater than $70 \mathrm{~mm}(2.75 \mathrm{in})$ and have a rated wattage between 40 and $205 \mathrm{~W}$. The minimum efficacies for incandescent reflector lamps are shown in Table 14.

\subsection{ASHRAE/IES Standard 90}

ASHRAE/IES Standard 90, "Energy Efficient Design of New Buildings Except Low-Rise Residential Buildings," is an energy conservation model which provides guidelines for determining the energy efficiency of individual building systems such as the building envelope, lighting, HVAC and service water heating systems and/or the integrated assembly of those systems. As a result, the standard presents two paths for demonstrating the energy efficiency of a building. The simplest path is a System/Component path where each of the independent systems must comply with prescriptive or system performance criteria on a units of energy or power basis. If the building does not comply under the System/Component path, the more complex yet flexible Building Energy Cost Budget path is available. The Building Energy Cost Budget path limits the annual energy cost for the building rather than the Btu, $\mathrm{kWh}$ or $\mathrm{kW}$ that can be consumed by the individual building systems. This path is intended to allow designers the freedom to implement creative energy conservation measures which would not have met the criteria set forth in the System/Component path such as load shifting and alternative fuels. It should be noted however that the basic requirements described in the System/Component path serve as the basis for the Building Energy Cost Budget path. For this reason, the System/Component path will be the focus of this discussion and the reader is referred to ASHRAE 90.1-1989 for a complete description of the Building Energy Cost Budget path.

The lighting portion of the System/Component path essentially sets forth basic requirements for interior and exterior lighting power allowances, minimum numbers of controls, lighting power control credits and ballasts. Our discussion begins with determining the exterior and interior lighting power allowances.

The maximum amount of energy an exterior lighting system may consume is limited by the Exterior Lighting Power Allowance (ELPA). The ELPA is based on 1) a given number of watts per unit length for doorways without canopies and 2) watts per unit area for canopied areas, driveways, parking lots and garages, exterior building surfaces, outdoor storage and recreation areas.

The interior lighting power allowance (ILPA) is a bit more complex and is determined based on either Prescriptive Criteria or System Performance Criteria. The Prescriptive Criteria are best 
Table 13. US Fluorescent Lamp Efficiency Requirements.

\begin{tabular}{llcc}
\hline Lamp Type & $\begin{array}{c}\text { Nominal Lamp } \\
\text { Wattage }\end{array}$ & $\begin{array}{c}\text { Minimum } \\
\text { CRI }\end{array}$ & $\begin{array}{c}\text { Minimum Lamp } \\
\text { Efficacy } \\
\text { (LPW) }\end{array}$ \\
\hline 4-foot medium bi-pin & $>35 \mathrm{~W}$ & 69 & 75.0 \\
& $\leq 35 \mathrm{~W}$ & 45 & 75.0 \\
2-foot U-shaped & $>35 \mathrm{~W}$ & 69 & 68.0 \\
& $\leq 35 \mathrm{~W}$ & 45 & 64.0 \\
8-foot slimline & $65 \mathrm{~W}$ & 69 & 80.0 \\
& $\leq 65 \mathrm{~W}$ & 45 & 80.0 \\
8-foot high output & $>100 \mathrm{~W}$ & 69 & 80.0 \\
& $\leq 100 \mathrm{~W}$ & 45 & 80.0 \\
\hline
\end{tabular}


Table 14. US Incandescent Reflector Lamp Efficiency Requirements.

\begin{tabular}{lc}
\hline $\begin{array}{l}\text { Nominal Lamp } \\
\text { Wattage }\end{array}$ & $\begin{array}{c}\text { Minimum Lamp } \\
\text { Efficacy } \\
\text { (LPW) }\end{array}$ \\
\hline $40-50$ & 10.5 \\
$51-66$ & 11.0 \\
$67-85$ & 12.5 \\
$86-115$ & 14.0 \\
$116-155$ & 14.5 \\
$156-205$ & 15.0 \\
\hline
\end{tabular}


applied to buildings early in the design phase or to "generic" buildings where the tasks throughout the building are generally homogeneous such as those listed in Table 15. The ILPA for these types of buildings is determined by multiplying the gross lighted area (GLA) of the total building by the listed unit lighting power allowance (ULPA) for the building's size classification. If more than 10 percent of the gross lighted area in a building is devoted to a particular task such as a garage in an office building, then each of the major ( $>10$ percent GLA) task areas is multiplied by the appropriate ULPAs. The sum of the individual ILPAs is equal to the total building ILPA.

Clearly, the Prescriptive Criteria present very simple computational procedure in that only a limited number of building types are represented. In contrast, the System Performance Criteria are more sensitive to space configurations and to small areas with demanding tasks that may require more light. As a result, the System Performance Criteria provide a more accurate assessment of the energy consumed by a building's lighting system.

The System Performance approach involves determining the lighting power budgets (LPB) for each space which are then summed and amended with a power allowance for unlisted spaces to determine the building's ILPA. Specifically, the lighting power budget for each space is determined as

$$
\mathrm{LPB}=\mathrm{A} \times \mathrm{UPD} \times \mathrm{AF}
$$

where

LPB = lighting power budget for the given area, $\mathrm{W}$

$$
\begin{aligned}
& A=\text { area of the space, } m^{2} \\
& U P D=\text { unit power density, } W / m^{2}
\end{aligned}
$$

$$
\mathrm{AF}=\text { area factor of the room. }
$$

The area of the space is equal to the gross floor area of the space; the UPD varies with the visual demands of the tasks in specific spaces such as drafting rooms, jail cells, nursing stations, and operating rooms; and, the area factor is a multiplier which is sensitive to room geometry. For example, for a given floor area, the area factor increases for higher ceilings to account for the greater volume of the space which decreases the amount of light falling on the task area.

In addition to single use spaces such as waiting rooms, special rooms such as multiple-purposes spaces or spaces containing multiple tasks are also addressed. Multi-purpose rooms are permitted an increase in the UPD by a factor of 1.5 to allow for the inclusion of a supplementary lighting system if two conditions are met. First, the connected load of the supplementary system may not be more than half the LPB of the original lighting system; and second, it must be independently controlled. In large rooms containing simultaneous activities, the LPB is based on a weighted average of the UPDs for the given tasks as a function of the areas occupied by those tasks.

Ultimately, the total system performance is equal to the sum of the LPBs of individual spaces plus an allowance of $2.2 \mathrm{~W} / \mathrm{m}^{2}$ for the unlisted area of the building. The unlisted area generally the floor area covered by walls and partitions and is equal to the gross floor area minus the area of the individual spaces. In effect, this increases slightly the overall power budget for a building and allows the lighting designer a slight cushion for designing within the power restrictions without under designing. 
Table 15. Prescriptive Unit Lighting Power Allowance (ULPA), $W / \mathrm{m}^{2}$ Gross Lighted Area of Total Building.

\begin{tabular}{|c|c|c|c|c|c|c|}
\hline $\begin{array}{l}\text { Building Type } \\
\text { Or Space Activity }\end{array}$ & $\begin{array}{c}0 \text { to } \\
200 \mathrm{~m}^{2}\end{array}$ & $\begin{array}{l}201 \text { to } \\
1000 \mathrm{~m}^{2}\end{array}$ & $\begin{array}{l}1001 \text { to } \\
2500 \mathrm{~m}^{2}\end{array}$ & $\begin{array}{l}2501 \text { to } \\
5000 \mathrm{~m}^{2}\end{array}$ & $\begin{array}{l}5001 \text { to } \\
25000 \mathrm{~m}^{2}\end{array}$ & $>25000 \mathrm{~m}^{2}$ \\
\hline \multicolumn{7}{|l|}{ Food Service } \\
\hline Fast Food/Cafeteria & 16.15 & 14.85 & 14.42 & 14.20 & 14.10 & 14.00 \\
\hline Leisure Dining/Bar & 23.68 & 20.56 & 18.41 & 16.79 & 15.72 & 15.07 \\
\hline Offices & 20.45 & 19.48 & 18.51 & 17.76 & 16.90 & 16.15 \\
\hline Retail & 35.52 & 33.15 & 30.46 & 26.91 & 24.54 & 22.60 \\
\hline $\begin{array}{l}\text { Mall Concourse } \\
\text { multi-store service }\end{array}$ & 17.22 & 17.00 & 16.36 & 15.72 & 15.39 & 15.07 \\
\hline Service Establishment & 29.06 & 25.51 & 22.39 & 20.67 & 19.38 & 18.30 \\
\hline Garages & 3.23 & 3.01 & 2.58 & 2.37 & 2.26 & 2.15 \\
\hline \multicolumn{7}{|l|}{ Schools } \\
\hline Preschool/elementary & 19.38 & 19.38 & 18.51 & 17.76 & 16.90 & 16.15 \\
\hline Jr. High/High School & 20.45 & 20.45 & 20.24 & 19.70 & 18.94 & 18.30 \\
\hline Technical/Vocational & 25.83 & 25.08 & 23.36 & 21.64 & 19.81 & 18.30 \\
\hline Warehouse/Storage & 8.61 & 7.10 & 6.02 & 5.17 & 4.63 & 4.31 \\
\hline
\end{tabular}

(C1989 American Society of Heating Refrigerating and Air-Conditioning Engineers, Inc., Atlanta, GA. Used by permission from ASHRAE/IES $90.1-1989$. 
Regardless of the method used to determine the ELPA and the ILPA, buildings are considered to be in compliance if the actual interior and exterior connected lighting power (CLP) does not exceed the respective allowances. Note that the standard does allow tradeoffs. For example, the CLP for individual spaces is not limited by that space's LPB so long as the total CLP for the interior or exterior of the building does not exceed its respective lighting power allowance. A tradeoff between interior and exterior lighting power allowances is not permitted.

Beyond power allowances, ASHRAE/IES 90.1-1989 also recognizes the cost saving benefits of controls by requiring all lighting systems, except for emergency or exit lighting, to be provided with manual, automatic or programmable controls. The number of controls required for each system is determined through a two-stage process. First, the minimum number of control points for a given space is determined. A space bounded by walls or ceiling-height partitions is required to have at least one lighting control point. In addition, that space must have one control point for each task location within the space or one control point for every 42 square meters, whichever is larger. Then, after determining the number of lighting control points, the minimum number of controls is determined. Because some control types are equivalent to more than one control point (see Table 16), the minimum number of controls required within a space varies depending upon the type of control chosen. An additional requirement is that there must be at least one control for every $1500 \mathrm{~W}$ of connected lighting power within a space. While the previous requirements are for interior spaces, the standard requires the controls for exterior lighting to be timers, photocells or a combination thereof if the lighting is not intended for continuous 24 hour use. Additionally, timers are required to be adjustable for variations in seasonal daylight availability.

ASHRAE/IES 90.1-1989 also encourages the use of more advanced lighting control strategies. Increases in the connected lighting power are permitted if the increased load is controlled by automatic control devices such as occupancy sensors, daylight sensors, lumen maintenance controls, or programmable timing devices. Lumen maintenance is a technique used to provide relatively constant light output during the life of a lamp. Typically, this involves dimming the lamps to a larger extent at the beginning of their life and decreasing the dimming as the lamp output decreases with age in an effort to maintain the number of lumens produced by the lamp. In any case, the claiming of such credits is subject to specific limitations.

The fourth basic requirement is for ballasts. ASHRAE/IES 90.1-1989 adopts the Federal Ballast legislation mentioned earlier with minor exceptions. First, Standard 90 establishes the minimum lamp starting temperature to be $4.4^{\circ} \mathrm{C}$ rather than the $-18^{\circ} \mathrm{C}$ stipulated in the US Federal guidelines. In addition, it requires lamps that would have traditionally been operated with one lamp ballasts to now be wired with a two lamp ballast and a lamp in a nearby luminaire.

Although the System/Component path is written in a system by system approach, it establishes flexible design criteria by allowing tradeoffs between systems which limit a building's total energy consumption as a composite of systems rather than limiting the consumption of each system individually. As a simple example, skylights in a roof could easily drive the Overall Thermal Transmittance $\left(\mathrm{U}_{\mathrm{o}}\right)$ of a building out of compliance. However, in exchange for the inflated $\mathrm{U}_{\mathrm{o}}$, ASHRAE/IES 90.1-1989 credits the lighting system with energy conservation if automatic lighting controls for daylighting are employed. Thus, the extra energy used because of the less efficient building envelope will be offset by the energy savings of the lighting system due to the daylight contributed by the skylights and the automatic lighting controls. 
Table 16. Control Types and Equivalent Control Points.

Equivalent Number

Type of Control of Control Points

Manually operated on-off switch

Occupancy sensor

Timer - Programmable from the space being controlled

Three level, including off, step control or pre-set dimming

Four level, including off, step control or pre-set dimming

Automatic or continuous dimming

3

(C1989 American Society of Heating Refrigerating and Air-Conditioning Engineers, Inc., Atlanta, GA. Used by permission from ASHRAE/IES 90.1-1989. 


\subsection{California}

The 1992 Energy Efficiency Standards for Nonresidential Buildings, High-Rise Residential Buildings and Hotels/Motels is a portion of the California Code of Regulations, Title 24 intended to promote the responsible and efficient use of energy in the state of California. The regulations are very comprehensive addressing the building envelope, domestic hot water and the mechanical and electrical systems. Designers are provided two options, a prescriptive approach and a performance approach, to demonstrate building compliance. Regardless of the chosen option, each system must meet individual mandatory restrictions and compliance may be demonstrated either for an individual system or a complete building by showing that the actual energy consumption is less than the allowable energy consumption.

This section will describe the Building Energy Efficiency Standards of Title 24 as they apply to lighting systems. To begin, a description of the mandatory restrictions is provided. Generally, the mandatory restrictions are limited to specifying criteria for control systems as well as minimum criteria for fluorescent lamp ballasts and luminaires that use fluorescent lamps. It should be noted, however, the mandatory requirements for fluorescent lamp ballasts and luminaires that use fluorescent lamps, are actually regulated by the Appliance Efficiency Standards of Title 20. The remainder of the section describes both the Prescriptive and Performance approaches to determining a building's total Allowable Lighting Power and concludes with a description of the method used to calculate the Actual Lighting Power including the permitted increases for lighting control credits.

\subsubsection{Mandatory Requirements}

The mandatory measures are requirements every building must meet regardless of the approach chosen to demonstrate compliance. For the most part, the requirements are limited to lighting control systems and strategies. Similar to many codes, the California standards require that independent lighting controls be located within the space whose lights they are controlling. This effectively eliminates the possibility of gang switching of multiple rooms, except for public areas. Here, the controls may be located in a separate location provided that some type of feedback is provided at the switch indicating the on/off status of the lighting equipment.

In addition to the switching proximity requirement, most areas are also required to be switched so that one half the load can be shed at a given time without losing use of the space. This is easily accomplished by one of three methods: dimming, alternate switching of luminaires or alternate switching of lamps within luminaires. Some exceptions to this requirement are small rooms with one luminaire, corridors, and spaces with a lighting power density less than $12.9 \mathrm{~W} / \mathrm{m}^{2}$.

Daylit spaces larger than $23.2 \mathrm{~m}^{2}$ also have special control requirements. In particular, luminaires contained in a space receiving daylight from a window or skylight must be switched so that half the lamps can be extinguished. The daylit space requirement is in addition to the bi-level switching requirement described earlier and the code provides possible solutions for meeting both requirements.

Display lighting is required to be switched separately on circuits rated at 20 amps or less. This requirement fulfills two purposes. First, it permits the general lighting system to be turned on without the display lighting during times when the display lighting is unnecessary. Second, it permits small portions of the display lighting to be turned on in situations where only limited display lighting is desired. 
Another control requirement is for separately metered spaces larger than $464 \mathrm{~m}^{2}$. These spaces are required to have automatic shut-off control systems incorporating a manual switch that allows the system to be overridden for a period of two hours or less. Lighting exempt from this requirement includes emergency egress lighting unless it consumes more than $5.4 \mathrm{~W} / \mathrm{m}^{2}$. Finally, exterior lighting served from a panel board within the building must be controlled by a directional photocell or an automatic time clock that can be programmed for seasonal variations.

Beyond control strategies, other mandatory requirements include tandem wiring of one- or threelamp fluorescent luminaires, certification of automatic lighting control devices by the California State Energy Commission before installation in a building, and certification of fluorescent luminaires and ballasts. It was noted earlier that certification of fluorescent ballasts and luminaires are regulated by Title 20 . It is presumed that the ballast requirements are similar to the Federal legislation described earlier.

\subsubsection{Determining Building Compliance}

A building complies with the energy standards when the mandatory requirements are met and the Actual Lighting Power is less than the Allowed Lighting Power. The Allowed Lighting Power may be determined by one of two approaches - the Prescriptive Approach or the Performance Approach. The Prescriptive Approach allows for varying degrees of flexibility by allowing the Allowed Lighting Power to be determined by one of three methods. These include the Complete Building Method, the Area Category Method and the Tailored Method, listed in increasing degree of complexity. The Performance Approach is perhaps the most flexible because it considers a building's total energy consumption rather than the consumption of individual systems.

\subsubsection{Prescriptive Approach to Determining Allowed Lighting Power}

A building complies with the energy code under the prescriptive approach if the Actual Lighting Power (adjusted) is less than the Allowed Lighting Power. The Allowed Lighting Power is the total number of watts per square meter a building is permitted to have connected based on space usage. It can be established according to one of three methods - the Complete Building Method, the Area Category Method, or the Tailored Method. Once the Allowed Lighting Power is determined for the composite building, the code does not restrict how the power is distributed within the structure. This is intended to allow designers more flexibility in creating visual environments that are both pleasing and comfortable.

\subsection{Complete Building Method}

The Complete Building Method is perhaps the simplest method for determining the Allowed Lighting Power. It can only be applied when all areas of the building are conditioned spaces (finished for occupancy) and involves multiplying the conditioned floor area of the building by the power density established in the code for the given building type. The power densities used in the Complete Building Method are given in Table 17.

\subsection{Area Category Method}

The Area Category Method of determining the Allowable Lighting Power is nearly identical to the Complete Building Method. The difference lies in the fact that the Area Category Method permits different power densities for individual spaces within a building. The Allowable Power Density is calculated by multiplying the total area of like-use spaces by the appropriate power density and summing them to determine a total limit. In addition, the Area Category Method allows for an additional power allowance for chandeliers and wall sconces in auditoria, hotels, malls, arcades, 
Table 17. Maximum Power Densities for Buildings Based on General Use.

\begin{tabular}{lc}
\hline Type of Use & $\mathrm{W} / \mathrm{m}^{2}$ \\
\hline $\begin{array}{l}\text { General Commercial and } \\
\text { Industrial Work Buildings }\end{array}$ & 12.9 \\
Grocery Store & 19.4 \\
$\begin{array}{l}\text { Industrial and Commercial } \\
\text { Storage Buildings }\end{array}$ & 8.6 \\
Medical Buildings and Clinics & 16.1 \\
Office Building & 16.1 \\
Religious Worship, Auditorium & 21.5 \\
and Convention Centers & \\
Restaurants & 16.1 \\
Retail and Wholesale Store & 21.5 \\
Schools & 19.4 \\
Theaters & 1.5 \\
All Others & 8.6 \\
\hline
\end{tabular}

From Nonresidential manual for compliance with the 1992 energy efficiency standards by the California Energy Commission, 1992, p.5-17. 
atria, houses of worship, and performance theaters. The power density allowances for spaces under the Area Category Method are given in Table 18.

\subsection{Tailored Method}

The Tailored Method is by far the most complex of the Prescriptive Approaches. Just as the Area Category Method was a more detailed version of the Complete Building Method, the Tailored Method is a more detailed version of the Area Category Method. The difference lies in the fact that the Allowable Power Limit in the Tailored Method accounts for the differing amounts of light required for different tasks within a given space as determined with the IES Illuminance Selection Procedure.

The Illuminance Selection Procedure outlines a process whereby the amount of light required to complete a certain task can be determined. The determining factors include the nature of the task including its detail and contrast, the observer's age, the importance of the task and the surface reflectances of the room in which the task is to be completed. Based on the difficulty of the task, each task has been assigned, by consensus, to one of nine illuminance categories labeled A through I with respective illuminances of 30 to 15000 lux. Within each category three illuminances are provided. Then, depending upon the other mentioned factors, a weighting system is used to determine which of the three illuminances is best suited to the space. For a more comprehensive treatment of the Illuminance Selection Procedure, the reader is encouraged to consult the second chapter of the IES Lighting Handbook, Applications Volume.

If the Illuminance Selection Procedure analysis places the task in categories A through E, a lighting power density is determined for a space as a function of both the Room Cavity Ratio (RCR) and the task's illuminance category. If the Illuminance Selection Procedure analysis places the task in categories $\mathrm{F}$ through $\mathrm{I}$, the power density is determined as a function of the task area and the distance from the source to the task or "throw distance." When the throw distance is greater than 4.6 meters, a multiplier from Table 19 is applied to the appropriate lighting power density.

Finally, after determining the power density for each task, the Allowable Power Limit for that task and the area it occupies is calculated by multiplying the task's power density by the task area. The task area is the area bound by floor-to-ceiling partitions. Partial height partitions are not considered appropriate boundaries for task areas. If, however, the task is a display, the task area is limited to the actual area of the display.

The total Allowed Lighting Power then is the sum of the powers for all spaces and tasks.

\subsubsection{Performance Approach to Determining Allowed Lighting Power}

An alternative approach to determining the Allowed Lighting Power for a building is the Performance Approach. In this approach, a building's thermal behavior and energy consumption is predicted using a computer program. The analysis results in a Proposed Design Energy Use for the building which is the sum of each system's energy use. At the same time, the Standard Design Energy Budget for the building is determined using a standardized method. Again, the sum of individual system energy consumption is the Standard Design Energy Budget. If the Proposed Design Energy Use is less than a Standard Design Energy Budget, the building is said to comply. In this way, the energy consumed by individual systems may be larger than the predicted values of the Standard Design Energy Budget so long as the combined energy use of all systems does not exceed the total standard budget. 
Table 18. Maximum Power Densities for Spaces Based on General Use.

\begin{tabular}{lc}
\hline Primary Function & $\mathrm{W} / \mathrm{m}^{2}$ \\
\hline Auditorium & 21.5 \\
Bank/Financial Institution & 19.4 \\
Classrooms & 21.5 \\
Convention, Conference, and & 17.2 \\
Meeting Centers & \\
Corridors, Restrooms, and & 8.6 \\
Support Areas & \\
Dining & 12.9 \\
Exhibit & 24.8 \\
General Commercial and & 14.0 \\
Industrial Work & \\
Grocery & 21.5 \\
Hotel Function & 24.8 \\
Industrial and Commercial Storage & 6.5 \\
Kitchen & 23.7 \\
Lobbies: & \\
Hotel Lobby & \\
Main Entry Lobby & 24.8 \\
Malls, Arcades and Atria & 17.2 \\
Medical and Clinical Care & 12.9 \\
Office & 19.4 \\
Precision Commercial and/or & 21.5 \\
Industrial Work & \\
Religious Worship & 23.7 \\
Retail Sales, Wholesale Showrooms & 23.7 \\
Theaters: & \\
Motion Picture & 10.8 \\
Performance & 16.1 \\
\hline
\end{tabular}

From Nonresidential manual for compliance with the 1992 energy efficiency standards by the Califomia Energy Commission, 1992, p.5-19. 
Table 19. Power Density for Illuminance Categories F Through I as a Function of Task Area and Throw Distance.

\begin{tabular}{ccc}
\hline & $\begin{array}{c}\text { Task Area }<.2 \mathrm{~m}^{2} \\
\text { and } \\
\text { Inluminance }\end{array}$ & $\begin{array}{c}\text { Task Area }>.2 \mathrm{~m}^{2} \\
\text { and }\end{array}$ \\
Category & Throw Distance $>2.4 \mathrm{~m}$ & Throw Distance $<2.4 \mathrm{~m}$ \\
\hline F & 107 & 53.5 \\
H & 280 & 140 \\
I & 678 & 339 \\
& 1400 & 700
\end{tabular}

From Nonresidential manual for compliance with the 1992 energy efficiency standards by the California Energy Commission, 1992, p.5-24. 


\subsubsection{Determining Actual Lighting Power}

The Actual Lighting Power is the sum of the connected watts in the building based on the same areas used to determine the Allowed Lighting Power and may be adjusted with lighting control credits earned by installing optional automatic controls.

Automatic lighting controls take many forms including electrical controls such as occupancy sensors, dimming systems, lumen maintenance controls, and automatic timers. Additional credits are earned for controls that modify lamp output based on daylight contribution to the space. Control credits are accounted for in the form of a multiplier which may only be used to adjust the wattage under the control's jurisdiction. Power savings adjustment factors range from 0.05 for automatic timers to 0.60 for occupancy sensors installed in rooms used exclusively for storage. In general, however, the average factor is about 0.3 .

Two special cases receive special consideration when the Actual Lighting Power is calculated. These are incandescent medium base sockets and track lighting. Incandescent medium base sockets present an unusual situation in that they accept lamps of varying wattages. Thus, it is possible to install a higher wattage lamp than specified. To account for the possible discrepancies, the code requires the larger of: (a) the total design wattage; or (b) 50 percent of the fixture's listed lighting power capacity; to be used in the Actual Lighting Power calculation.

Similarly, the Actual Lighting Power for track lighting must use the larger of the following two values: (a) the total luminaire design wattage for each track; or (b) 148 watts per meter which is equal to 50 percent of the National Electric Code's rating of 296 watts per meter. In addition, tracks fed by permanently installed transformers for low voltage lighting are required to use the volt ampere (VA) rating of the transformer as the track's Actual Lighting Power.

\subsection{Massachusetts}

Article 31 of The Massachusetts State Building Code outlines energy conservation measures required in most new buildings in Massachusetts. Buildings meet compliance standards if: (a) each of the building systems independently consume less energy than permitted by the code; (b) total building energy consumption is less than the sum of the permitted consumption of individual systems; or (c) the building uses nondepletive energy supplies such as solar, geothermal or wind energies. Since electric lighting primarily depends upon depletive energy sources, further discussion will be limited to describing the individual system and building compliance paths.

\subsubsection{Individual System Compliance - The Lighting System}

If it has been determined that a particular building's compliance with energy requirements is to be based on the individual system approach, all energy consuming systems are required to meet minimum standards. In the case of the lighting system, two basic requirements must be satisfied: (1) the system must incorporate a minimum number of lighting controls; and (2) it may not consume more energy than the Building Lighting Power Limit allows. The present discussion will begin with controls requirements and continue with the Building Lighting Power Limit.

Lighting controls are a major factor in energy conservation. Therefore, like most building codes, the Massachusetts Building Code requires the inclusion of controls. Minimally, the Massachusetts code requires all rooms to have independent controls effectively eliminating the possibility of gang switching rooms. Further, the controls for each space are required to be accessible to all occupants unless it is a public space such as a lobby, retail store, or storeroom. In these cases, the controls may be centrally located in a remote location. 
The number of controls required in a space is based on the area of the space and the connected load within that space. First, a single switch may not control more than 70 square meters. Further, within that space the switch may not control more than $1600 \mathrm{~W}$ connected load in a $277 \mathrm{~V}$ system or $1250 \mathrm{~W}$ in a $120 \mathrm{~V}$ system. An exception to this potentially complicated scenario is public spaces where the number of controls is the greater of: (a) three control points; or (b) one control point for each $1500 \mathrm{~W}$ of connected lighting load. If automatic controls are employed, the number of controls may be reduced. For example, an occupancy sensor is equivalent to two control points while automatic or continuous dimming is equivalent to three control points. This concept is very similar to the ASHRAE/IES Standard 90.

Exterior lighting fixtures are required to be automatically switched allowing them to be turned off during the daytime unless the lights are required for security measures.

Ballasts are required to meet minimum performance standards including minimum power factors and, in the case of fluorescent lamps, minimum Ballast Efficiency Factors (BEFs). Specifically, fluorescent lamp ballasts are required to meet the US Federal Ballast Legislation requirements previously outlined in this document. One exception for fluorescent ballasts is the lower minimum power factor, 0.60 as opposed to 0.90 , for ballasts designed to operate with a single F40T12 lamp. As an addition to the Federal requirements, the Massachusetts code requires one- and threelamp ballasts within a given proximity to be tandem wired in an effort to minimize the use of single-lamp ballasts.

The Massachusetts code further stipulates that all ballasts must have a power factor of 0.90 unless the ballasts are used with circline, compact fluorescent, or HID lamps less than $100 \mathrm{~W}$. Further, dimming ballasts are exempt from power factor and Ballast Efficiency Factor requirements.

The Building Lighting Power Limit (BLPL) is the sum of the Exterior Lighting Power Limit (ELPL), the Road and Grounds Lighting Power Limit (RLPL) and the Interior Lighting Power Limit (ILPL). Determining the Exterior and Road and Grounds Lighting Power Limits is very straightforward but does not permit a great deal of flexibility. Determining the Interior Lighting Power Limit is more complex but flexibility is granted by allowing the power budget to be determined either by prescriptive or system performance criteria. Tradeoffs among buildings are not permitted unless a multiple buildings facility is involved. In this case, only the power allowance for exterior lighting is eligible for tradeoffs among the buildings.

Exterior lighting power allowances are limited to a given number of watts per unit length of door openings if the entrance or exit is uncovered and limited to a power density for covered areas. In addition, the power allowance for roads and grounds is limited to a particular power density depending upon the type of road or parking lot. Public roads and parking lots are permitted higher power densities than are private roads and parking lots.

The Prescriptive Method for determining the Interior Lighting Power Limit applies only to permanently wired fixtures. The Interior Lighting Power Limit is equal to the sum of the watts permitted for use in various building areas. The watts permitted for each area are calculated by determining the usage of various building spaces and multiplying the gross area of the spaces by the permitted power density for that space.

The System Performance Method for determining the Interior Lighting Power Limit takes the Prescriptive Method one step further and includes the power consumption of supplemental lighting provided by non-permanently wired fixtures. It establishes the power allowance for individual spaces based on very specific space usages. For example, a space that may have been defined as a garage in the Prescriptive Method now requires the space usage to be specifically identified as a circulation space or a parking area within the garage. As a result, different power densities are 
permitted. Garage circulation is limited to $3.23 \mathrm{~W} / \mathrm{m}^{2}$ while parking areas are limited to 2.15 $\mathrm{W} / \mathrm{m}^{2}$. In the case where a space is used simultaneously for tasks with differing power allowances, the total power allowance for that space is an area weighted average. Similarly, multipurpose rooms, rooms designed to be used for multiple uses although not simultaneously, are permitted to have supplementary lighting systems with a power consumption less than 50 percent of the consumption of the primary system. In addition, the supplementary system must be controlled separately.

Once the power limits for particular tasks are determined, the lighting power budget for a given space is calculated by multiplying the area of the space by the allowable power density and an area factor for the space. The area factor is intended to modify the power limit recognizing the influence of a room's geometry on the ability of a luminaire to deliver light to the work surface. For example, two rooms with equal floor spaces but different ceiling heights have different area factors. The room with a higher ceiling has a greater area factor to account for the fact that the light source is further from the task surface and will, therefore, require more luminaires to provide the required amount of light on the task surface.

Finally, the total Interior Lighting Power Limit is equal to the sum of the individual space power allowances and is used to determine compliance for interior spaces. The actual connected lighting power may not be larger than the ILPL if the lights are controlled by normal on/off switches. If, however, automatic controls are employed in the system, credits may be taken which allow the actual connected lighting power to exceed the ILPL. Automatic control devices are listed as occupancy sensors, daylighting sensors, lumen maintenance controls, and programmable timing controls. Individually, occupancy sensors allow for the greatest increase (42 percent) in connected load while lumen maintenance allows for the smallest increase (11 percent). Automatic controls are permitted to be combined in particular configurations. These combinations and their associated increases include: (a) occupancy sensors with daylighting sensors (66 percent); (b) occupancy sensors with lumen maintenance controls (53 percent); and (c) occupancy sensors with both daylight sensors and lumen maintenance controls (81 percent).

The application of control credits to the ILPL are, of course, restricted. Restrictions include the exclusion of dimming controls for incandescent lamps and luminaires; only one credit may be taken for a given space or luminaire; and programmable timing controls must be capable of accepting different schedules accounting for weekdays and weekends. In addition, daylighting controls must have the capacity to cut power consumption of luminaires within a daylighted space to less than 50 percent of maximum power but may not cut the power consumption of luminaires outside the daylighted area by more than 50 percent. Of interest to the daylighting control restriction is the fact that guidelines for defining a daylighted area are not provided.

\subsubsection{Design by System Analysis}

An alternative means of determining compliance with the Massachusetts Energy Code is a complete building analysis. If the total building energy consumption is less than the sum of the energy allowances for each system, the building is said to comply with the code. This path to compliance allows some systems to exceed their consumption allowances as long as those increases are offset by savings accrued by other systems.

\subsection{New York}

The New York State Energy Conservation Code sets forth minimum design requirements for new buildings and buildings undergoing substantial renovation. Similar to ASHRAE/IES Standard 90 , it regulates the energy consumption of building envelopes, HVAC, service water heating, electrical 
and lighting systems. However, it is not as flexible as Standard 90; the energy used by each system must be less than the maximum permitted by the code. It does not allow tradeoffs among systems. Additionally, it establishes minimum efficiencies for individual components of systems.

A building lighting system is required to be designed around some basic requirements including the number and location of controls as well as minimum efficiencies for fluorescent lamp/ballast combinations and luminaires. All rooms are required to have at least one control for the general lighting within a room although large rooms are required to have multiple switching points enabling the general lighting to be reduced by at least half. The exceptions to this requirement are large spaces intended for 24 hour continuous occupancy such as lobbies, storerooms and retail sales floors. In addition, those rooms not used on a continuous 24 hour schedule are required to have automatic devices capable of limiting the hours of lighting to the room's occupancy schedule. Accent and task lighting is required to be controlled independently from the general lighting system. Exterior lighting not intended for 24 hour continuous operation is required to be controlled by a timer, photocell or combination thereof with the stipulation that the system is adjustable to account for seasonal and daily variations.

The New York regulations also require certain fluorescent lamps to have minimum efficacies and color rendering indices. These include restrictions for the most commonly specified lamps for commercial applications: F40T12, F96T12, F96T12HO, and F40T12U. The minimum requirements for these lamps are shown in Table 20. Effectively, these minimum efficacies prohibit the use of all F40T12, F96T12, F96T12HO and F40T12U lamps unless the phosphor coating is a rare earth phosphor. All other lamps remain unrestricted.

Similar to fluorescent lamps, only a few types of fluorescent lamp ballasts are regulated. The regulations establish minimum ballast efficiency factors, shown in Table 21, and require each of the specified ballasts to have a power factor of at least 0.90 . Note that these requirements are equivalent to the US Federal Ballast Legislation except for the added three-lamp ballast. Ballasts designed for lamps other than those given in Table 21 remain unregulated. In addition, the code requires three-lamp fluorescent luminaires to be tandem wired or to use three-lamp ballasts.

Luminaires for general lighting are the final major component required to have minimum efficiencies. Minimum efficiencies are based on the luminaire's physical configuration, lamp type and lumen distribution characteristics. The luminaire's distribution characteristic is defined as the ratio of the lumens produced in the conical segment of a sphere bound at a $40^{\circ}$ vertical angle to the lumens produced in the complete lower hemisphere. These values are shown in Table 22. Note that the dramatically higher values in parentheses will be the minimum efficiencies for equipment manufactured after January 1, 1995. If a luminaire does not meet the minimum efficiency requirements, however, it is not necessarily excluded from use. It may be used if the wattage of other conforming luminaires in the building is reduced to compensate for the added load of the non-conforming luminaires. As with lamps and ballasts, some luminaires are exempt from minimum efficiency requirements. These include luminaires designed for use with compact fluorescent or low voltage sources, chandeliers, and custom made fixtures.

In addition to requiring minimum efficiencies for lighting components, the interior and exterior lighting systems must also meet individually established criteria. The criteria for interior lighting systems is a maximum power density which is determined as a function of building type (office, store, education, library and recreation to name a few) and the area weighted average of the room cavity ratios for the building's spaces. Of interest is the fact that the power consumed by the system includes that of the lamps, ballasts, current regulators and the lighting controls. 
Table 20. Minimum Efficacies and Color Rendering Indexes for Certain Fluorescent Lamps Required by The New York Energy Code.

\begin{tabular}{lcc}
\hline Lamp Type & $\begin{array}{c}\text { Minimum Efficacy } \\
\text { (Initial Lumens per Watt) }\end{array}$ & Minimum CRI \\
\hline F40T12 & 75 & 67 \\
F96T12 & 80 & 67 \\
F96T12HO & 80 & 67 \\
F40T12U & 68 & 67 \\
\hline
\end{tabular}

From New York Energy Conservation Construction Code by the New York State Energy Office, 1991, p.41. 
Table 21. Minimum Ballast Performance Requirements Required by The New York Energy Code. These requirements are equivalent to the US Federal Ballast Legislation except for the added three-lamp ballast (*).

Ballasts Designed For the Operation of Nominal Input Voltage
Total Nominal Lamp Watts

Ballast Efficiency

Factor

$\begin{array}{llll}\text { 1 - F40T12 lamp } & 120 & 40 & 1.805 \\ & 277 & 40 & 1.805 \\ \text { 2 - F40T12 lamps } & 120 & 80 & 1.060 \\ & 277 & 80 & 1.050 \\ \text { 3* - F40T12 lamps } & 120 & 120 & 0.710 \\ & 277 & 120 & 0.710 \\ \text { 2 - F96T12 lamps } & 120 & 150 & 0.570 \\ & 277 & 150 & 0.570 \\ \text { 2 - F96T12HO lamps } & 120 & 220 & 0.390 \\ & 277 & 220 & 0.390\end{array}$

From New York Energy Conservation Construction Code by the New York State Energy Office, 1991, p.40. 
Table 22. New York Total Luminaire Efficiency, Minimum Performance.

\begin{tabular}{|c|c|c|c|}
\hline \multirow[b]{2}{*}{ Luminaire Type } & \multicolumn{3}{|c|}{ Luminaire Distribution Characteristics } \\
\hline & $\begin{array}{l}\text { Narrow } \\
>0.55\end{array}$ & $\begin{array}{c}\text { Moderate } \\
0.55-0.45\end{array}$ & $\begin{array}{l}\text { Wide } \\
<0.45\end{array}$ \\
\hline \multicolumn{4}{|l|}{ Fluorescent Lamps } \\
\hline Small Cell Louver & $25 \%(40 \%)$ & $50 \%(57 \%)$ & $50 \%(57 \%)$ \\
\hline Other Louver & $44 \%(55 \%)$ & $53 \%(62 \%)$ & $59 \%(66 \%)$ \\
\hline Wrap-around Diffuser/Lens & $64 \%(71 \%)$ & $64 \%(71 \%)$ & $64 \%(71 \%)$ \\
\hline Flat Diffuser/Lens & $53 \%(64 \%)$ & $53 \%(64 \%)$ & $53 \%(64 \%)$ \\
\hline All Others & $33 \%(49 \%)$ & $52 \%(60 \%)$ & $56 \%(72 \%)$ \\
\hline & \multicolumn{3}{|c|}{ All Lumen Distribution Characteristics } \\
\hline HID Lamps & \multicolumn{3}{|c|}{$40 \%(56 \%)$} \\
\hline \multicolumn{4}{|l|}{ Incandescent Lamps } \\
\hline Reflector Lamps & \multicolumn{3}{|c|}{$47 \%(66 \%)$} \\
\hline General Service Lamps & \multicolumn{3}{|c|}{$46 \%(59 \%)$} \\
\hline
\end{tabular}

From New York Energy Conservation Construction Code by the New York State Energy Office, 1991, p.42. 
Exterior lighting system criteria are very similar to that of ASHRAE Standard 90. Entrances and exits are limited to a certain number of watts per unit width of door opening while facades and covered entrances are limited based on power density.

\subsection{Summary}

This section has summarized the various approaches to regulating energy efficiency. At the Federal level, it appears that Canada is following the lead of the United States in regulating the energy efficiency of lighting components while individual state and ASHRAE guidelines supplement the component requirements with system performance requirements. The goals of the Federal requirements are to promote more energy efficient lighting technologies. To date we have seen the Federal regulations render some general fluorescent lamps obsolete based largely on the type of phosphor coating which controls the efficacy of the lamp. The use of magnetic ballasts has also been tightly regulated. The ultimate result of these regulations will likely be that some technologies will become obsolete. For example, high pressure mercury vapor lamps. Mercury. vapor lamps have the distinction of being less efficacious than metal halide lamps while also having a poorer color rendering index. As a result, the metal halide lamp is an attractive alternative for applications where mercury vapor lamps were formerly specified.

The goals of the state energy codes are very similar yet their mechanisms are different. The California and Massachusetts codes are the more progressive of the three while the New York code is the most restrictive. California and Massachusetts address the energy consumption of all building systems either on an individual or composite basis. For individual systems, lighting in particular, California and Massachusetts codes present a stratified approach to demonstrating conformance that engineers can use depending upon what is known about the intended use of the building. In addition, each of the codes bases conformance on a power density or consumption metric rather than an illuminance or light generating capacity metric. This allows engineers design flexibility while encouraging responsible energy use.

At the basic level, where not much detail is known about the specific use of the building, the California and Massachusetts codes allow for the permissible power density for the complete structure to be determined according to the structure's general use. If more space usage information is known, a more detailed analysis can involve determination of the power density for each individual space as a function of the specific tasks being performed in the space.

In addition to the allowable power densities, the California and Massachusetts codes emphasize the conservation benefits of lighting controls. In fact, in addition to minimum requirements, the codes often provide an incentive to incorporate more sophisticated controls. Usually, the incentive is in the form of a credit whereby the actual connected power density can be increased beyond the allowable power density. The magnitude of the increase is, of course, dependent upon how automated the control is.

In contrast to California and Massachusetts, New York limits the energy consumption of individual systems. The interior lighting budget is determined based on the basic use of the space and does not allow the option of determining the power budget based on individual task requirements such as contrast. This is restrictive in that a small area of a building may require more energy because of the nature of the task and yet that extra energy must be allocated at the expense of another area in the building.

Power densities are determined for both interiors and exteriors. California uses the basic philosophy that the total consumption of a building must be within the allowable limit and thus 
tradeoffs between the interior and exterior power budgets are permissible. Massachusetts and New York, on the other hand, treat the interior and exterior separately and do not allow for tradeoffs.

Beyond prescriptive criteria, California and Massachusetts establish performance criteria as an alternative means for demonstrating conformance. Building performance criteria are for the total building energy consumption. Generally, the maximum allowable power consumption is the sum of the allowable consumption permitted under the prescriptive criteria. If the total building consumption is less than the allowable, the building complies. The purpose of this path to demonstrating building conformance is to encourage building designers to apply new and innovative energy technologies and reward their efforts by permitting other building systems to consume more energy than otherwise allowed.

In addition to establishing limits for energy consumption, each state energy code incorporates the US Federal Ballast Legislation which stipulates minimum ballast efficiency and power factors for F40T12, F96T12 and F96T12HO lamps. Unlike Massachusetts and California, New York also establishes minimum lamp efficacies and luminaire luminous efficiencies. This element of the New York code is strong and looks to grow even stronger. In 1995, the minimum luminaire luminous efficiencies will increase dramatically.

Overall, some general observations about the codes can be made. First, California has written a very detailed code offering the greatest number of paths to demonstrate compliance. Second, the power densities established by each of the codes are very similar and appear to be derived from ASHRAE/IES Standard 90. Third, lighting controls play a very predominant role in ensuring energy efficiency eventhough they are under user control to a greater extent and more easily defeated.

\section{Conclusion}

Recent concerns about global warming and our dependency on limited energy resources has prompted a number of initiatives aimed at regulating the energy consumption of architectural lighting systems. As a result, the current test procedures referenced by the legislation must be evaluated to assure their accuracy and appropriateness for evaluating the energy efficiency of lighting components and systems. To that end this report has surveyed the myriad of published national and international test methods and regulatory efforts. The report begins by providing a brief description of how each of the lighting components operates before describing the test procedures used to evaluate each of the components. The description of the various test procedures also identifies inconsistencies in the test methods and describes why the data derived from the procedures is inappropriate for determining the efficiency of lighting systems and component combinations. Finally, the report discusses the major legislative efforts currently underway in Canada and the US.

The review of component test methods reveals that the methods are remarkably harmonized in their requirements with only minor inconsistencies in testing requirements. Historically, the data have been used to determine whether particular components are electrically compatible, meaning that the voltage and current supplied by a ballast will permit a certain lamp to operate without suffering any detrimental effects such as a shortened life. To serve this purpose, standards have necessarily established precise baseline operating conditions which include a very specific power supply, thermal environment, and auxiliary equipment (standard reference ballasts and lamps) characteristics. Unfortunately, none of these conditions typically exist in buildings where lighting systems are installed. For example, the power supply to a building can be expected to fluctuate much more than the 0.1 percent required by the test procedures and fluorescent luminaires can be expected to be mounted in ceiling plenums where the operating temperatures are significantly higher than the ambient test temperature of $25^{\circ} \mathrm{C}$. As a result, the data cannot be legitimately 
extended to permit accurate predictions of how different lighting components will interact and operate as a lighting system, which is becoming increasingly important with stricter energy efficiency legislation. Thus, there is a need to develop more comprehensive test procedures.

The need to develop more comprehensive test methods stems from the fact that there are two different approaches to regulating energy efficiency: establishing minimum performance requirements for individual lighting components and/or lighting systems. These approaches are evident in the current legislation being passed at state and national levels. At the national level, the US has taken a component based approach to defining energy efficiency in a multi-phased process. The initial phase established minimum efficiencies for ballasts that operate with the fluorescent lamps most commonly found in commercial spaces. These include F40T12, F96T12 and F96T12HO lamps. Consequently, the legislation effectively prohibits the use of aluminum windings in exchange for copper windings in electromagnetic ballasts and encourages the use of electronic ballasts.

The second phase of the US energy legislation targets the fluorescent lamps that operate on the ballasts regulated in the ballast legislation as well as reflector type incandescent lamps. For fluorescent lamps, the legislation establishes minimum CRIs and lamp efficacies. The impact of the legislation is greatest on lamps that use standard phosphors. Because the standard phosphors cannot meet both the minimum CRI and efficacy requirements, they are prohibited from being sold for commercial applications. As a result, the more efficient tri-phosphor lamps will become standard equipment in commercial spaces. There are both advantages and disadvantages to this legislation. The advantages include the inherently higher CRIs of tri-phosphor lamps. There is evidence (Boyce, 1977) that higher CRIs may permit lower illuminances, and thus energy savings, in spaces while maintaining the same appearance created by lower CRI lamps. The savings in lower energy costs will, however, be offset to some degree by the higher first costs of triphosphor fluorescent lamps.

Similar to fluorescent lamps, general service incandescent reflector lamps, meaning lamps that operate at line voltage, have a medium screw base, and have an R or PAR shaped bulb, are regulated based on luminous efficacy. Two types of these lamps are currently on the market and the net effect of the legislation is that the less efficient of the two will no longer be appropriate for commercial applications. The less efficient lamp is characterized as having a tungsten filament enclosed in a glass bulb with an inert gas. The more efficient type replaces the tungsten filament with a small, more efficient, quartz halogen lamp. Similar to fluorescent lamps, the energy savings generated by the higher efficiency halogen lamps is tempered by the higher initial costs.

Subsequent phases of the US legislation will address luminaires and HID lamps.

Canadian efforts at regulating energy efficiency seem to be taking a slightly different course. Rather than legislating minimum efficiencies and referencing the test procedures whereby the ratings should be determined, the minimum efficiencies are, at least in the case of fluorescent ballasts, being directly incorporated into the testing procedures.

While the US federal approach to regulating energy efficiency is component oriented, individual state legislatures are supplementing the component requirements with system performance requirements. The system performance requirements address energy efficiency on two dimensions including the establishment of maximum allowable power loads and control strategies. Typically, the maximum allowable connected loads for buildings are determined through a variety of algorithms which vary from state to state. In general, the codes establish both maximum allowable interior and exterior loads to serve as design guidelines. Usually, the exterior limits are determined based on watts per unit area for covered areas and watts per unit length for doorways. Maximum interior loads are computed by a number of methods depending upon the use of the building and how much is known about the use of the interior space. If the building is early in the design 
phase, the power limit is determined as a product of the building floor area and the allowable power density based on the general use of the building. Then, as the spaces in the building become better defined, a more accurate method of determining the power budget is used. In most cases, the more accurate methods determine the power budget as a function of the floor area of the space, the physical geometry of the space and the visual demands of the task. Specifically, more visually demanding tasks are permitted higher power allowances than less difficult tasks.

A building can typically demonstrate compliance at an individual system level or as a complete building which is a composite of all the building systems. To demonstrate compliance at the system level, the connected interior and exterior loads must be less than the respective allowable loads. However, exceptions to this requirement are found in Standard 90 and the Massachusetts code. Standard 90 permits greater flexibility by not restricting where the load is applied, inside or outside, so long as the total connected load is less than the sum of the allowable interior and exterior loads. A similar variation on this provision is found in the Massachusetts code where the code permits the exterior load of a building complex to be shifted from one building to another with the restriction that the total connected exterior load for the complex is less than the sum of the allowable loads for the individual building exteriors. Note that this scheme for load shifting is not applicable to the interiors of buildings in the development.

Although there are restrictions on whether the loads can be shifted between the interior and exterior, there are no restrictions prohibiting load shifting within a building. This is seen as one of the positive attributes of this approach because it allows lighting designers some design flexibility. For example, the designer may be able to properly light a stairwell with less energy than allowed by the code. As a result, the unused power is not lost but can be shifted to the lobby where it may be needed to create a more pleasing environment than original power allowances would have permitted.

In contrast to individual system compliance, California and Standard 90 also permit a building to demonstrate compliance based on a composite of all the building systems. In this case, the total yearly energy consumption of the building is limited regardless of the energy consumption of the individual systems. This is seen as an advantage because it recognizes that buildings perform as a composite assembly of all the systems and it allows the building design team more flexibility in applying new energy technology without being penalized.

Further provisions of the state codes include mandatory control requirements which generally state that controls must be easily accessible to room occupants. Additionally, the codes provide for increasing the allowable connected load if automated controls are incorporated into the design. The magnitude of the increase is dictated by the degree of the control's automation. As an example, Standard 90 allows a greater increase in connected load if computer controlled dimming is incorporated in the system than if manual on/off switches are specified.

Clearly, the systems approach to regulating energy efficiency is attractive because of its flexibility. However, the approach is firmly based on the assumption that we are able to accurately quantify the energy consuming nature of lighting systems based on rated component data. Since it was suggested earlier that this is not the case, it is more evident than ever that there exists a great need for an expanded, more comprehensive battery of test procedures.

Treado and Collins (1991) proposed two alternative approaches to developing procedures for assessing lighting system performance after recognizing that the ideal and completely impractical approach to rating system performance involves testing every possible combination of lighting components. The first proposal requires all components to be categorized based on similar operating characteristics and system performance profiles to be developed for each of the group combinations. The authors point out that while this appears to be an attractive alternative, testing 
would be required to categorize the equipment and the number of resulting categories could still be very large. The second, and perhaps more attractive, proposal suggests that current test procedures could be expanded to allow more comprehensive data for individual components to be collected and later submitted to a computer modeling program for a system analysis.

In any case, the need for new test procedures exists and the data derived from such test methods should be more accurate, eliminating much of the uncertainty in lighting design. No longer would lighting designers and engineers experience large discrepancies between measured values of newly installed systems and the design predictions. Indeed, the data would advance the quantitative engineering of lighting systems and remove much of the guesswork out of analysis.

Consequently, better energy efficiency guidelines could be established. As it is, we do not know whether energy performance criteria are too stringent or not stringent enough. Experience tells us that we are at least in the ball park but, the fact is, we may be able to do better. 


\section{Bibliography}

American National Standards Institute. (1984). Fluorescent lamp ballasts - Methods of measurement. (ANSI C82.2-1984). New York.

American National Standards Institute. (1985). Ballasts for high-intensity-discharge and lowpressure sodium lamps (multiple supply type). (ANSI C82.4-1985). New York.

American National Standards Institute. (1985). Reference ballasts for high-intensity-discharge lamps - Methods of measurement. (ANSI/ASC C82.6-1985). New York.

American National Standards Institute. (1987). Electric lamps - Metal-halide lamps — Methods of measuring characteristics. (ANSI C78.387-1987). New York.

American National Standards Institute. (1989). Electric lamps - Mercury lamps - Methods of measuring characteristics. (ANSI C78.386-1989). New York.

American National Standards Institute. (1990). Electric lamps - High-pressure sodium lamps Methods of measuring characteristics. (ANSI C78.388-1990). New York.

American National Standards Institute. (1991). Electric lamps - Fluorescent self-ballasted lamps - Performance guide. (ANSI C78.5-1991). New York.

American National Standards Institute. (1991). Fluorescent lamps - Guide for electrical measurements (ANSI C78.375-1991). New York.

American Society of Heating, Refrigerating and Air-Conditioning Engineers \& Illuminating Engineering Society of North America. (1989). Energy efficient design of new buildings except new low-rise residential buildings (ASHRAE/IES 90.1-1989). Atlanta, GA: Author.

Boyce, P.R. (1977). Investigations of the subjective balance between illuminance and lamp color properties. Lighting Research and Technology, 9, 11-24.

California Energy Commission. (1992). Nonresidential manual for compliance with the 1992 energy efficiency standards. Sacramento, CA: State of California.

Canadian Standards Association. (1991). Fluorescent lamp ballast efficacy measurements. (CAN/CSA-C654-M91). Toronto.

Commission Internationale de l'Eclairage. (1973). Procedures for the measurement of luminous flux of discharge lamps and for their calibration as working standards. (CIE 25 (TC-1.2)). Paris.

Comprehensive National Energy Policy Act, 42 U.S.C. §6314.

Cooke, P. W. (1988). A summary of the new European Community approach to standards development. (NBSIR 88-3793-1). Washington, DC: National Institute of Standards and Technology.

Energy Information Administration. (1992). Energy consumption series: Lighting in commercial buildings. Washington DC, US Department of Energy, Office of Energy Markets and End Use, Energy Information Administration. 
Energy, Mines and Resources Canada. (1992). The Energy Efficiency Act, The Equipment Regulation and Labeling Program, A discussion paper on: "How we'd like it to work." Ottawa, Ontario: Author.

Illuminating Engineering Society of North America. (1984). Approved method for the electrical and photometric measurements of high intensity discharge lamps. (IES LM-51). New York.

Illuminating Engineering Society of North America. (1988). Approved method for the electrical and photometric measurements of fluorescent lamps. (IES LM-9). New York.

Illuminating Engineering Society of North America. (1991). Electrical and photometric measurements of single-ended compact fluorescent lamps. (IES LM-66). New York.

International Electrotechnical Commission. (1974). High-pressure mercury vapor lamps second edition. (IEC 188-74). Geneva.

International Electrotechnical Commission. (1980). High-pressure sodium vapor lamps first edition. (IEC 662-1980). Geneva.

International Electrotechnical Commission. (1984). Tubular fluorescent lamps for general lighting service fourth edition. (IEC 81-84). Geneva.

International Electrotechnical Commission. (1987). Single-capped fluorescent lamps - safety and performance requirements first edition. (IEC 901-87). Geneva.

International Electrotechnical Commission. (1988). Ballasts for discharge lamps (excluding tubular fluorescent lamps) performance requirements first edition. (IEC 923-88). Geneva.

International Electrotechnical Commission. (1988). Ballasts for tubular fluorescent lamps performance requirements first edition. (IEC 921-88). Geneva.

International Electrotechnical Commission. (1988). Self-ballasted lamps for general lighting services performance requirements first edition. (IEC 969-88). Geneva.

International Electrotechnical Commission. (1990). A.C. Supplied electronic ballasts for tubular fluorescent lamps - Performance requirements first edition. (IEC 928-90). Geneva.

Japanese Industrial Standards Committee. (1983). Ballasts for fluorescent lamps (JS C810883). Tokyo.

Japanese Industrial Standards Committee. (1985). High pressure mercury vapor lamps. (JIS C7604-85). Tokyo.

Japanese Industrial Standards Committee. (1987). Ballasts for high pressure mercury vapor lamps and ballasts for low pressure sodium lamps. (JIS C8110-87). Tokyo.

Japanese Industrial Standards Committee. (1988). General rules of testing method for lamps (JIS C7801-88). Tokyo.

Japanese Industrial Standards Committee. (1991). Total luminous flux measurements on discharge lamps used for photometric standards (JIS C7607-91). Tokyo. 
Kaufman, J. E. (Ed.). (1984). IES Handbook, Reference Volume. New York: Illuminating Engineering Society of North America.

Massachusetts. (1990). Energy conservation. The Massachusetts state building code, 780 CMR, Article 31, Boston, MA: State of Massachusetts.

Murdoch, J. B. (1985). Illumination engineering, From Edison's lamp to the laser. New York: Macmillan.

National Appliance Energy Conservation Amendments of 1988, 42 U.S.C. § 6201(a).

New York State Energy Office. (1991). New York State energy conservation construction code. Albany, NY: State of New York.

Piette, M. A., Krause, F. \& Verderber, R. (1989). Technology assessment: Energy-efficient commercial lighting. Berkeley: University of California, Lawrence Berkeley Laboratory, Applied Science Division.

Sylvania. (Undated A). Fluorescent lamps. (Engineering Bulletin 0-341). Danvers, MA: Author.

Sylvania. (Undated B). High intensity discharge lamps - Mercury lamps. (Engineering Bulletin 0-346). Danvers, MA: Author.

Sylvania. (Undated C). High intensity discharge lamps - Metalarc lamps. (Engineering Bulletin 0-344). Danvers, MA: Author.

Treado, S. J. \& Bean, J. W. (1992). The interaction of lighting, heating, and cooling systems in buildings. (NISTTIR 4701). Washington, DC: National Institute of Standards and Technology.

Treado, S. J. \& Collins, B. L. (1991). Requirements for performance testing and evaluation of lighting equipment. Proceedings of the IES Annual Conference, Montreal, Canada. 
Appendix A

Standard Test Methods Sorted By Standards Organization

Standard No.

Standard Title

Relevant Lighting

ANSI C78.1 (1978)

ANSI C78.1341 (1990)

ANSI C78.1342 (1985)

ANSI C78.1350 (1990)

ANSI C78.1351 (1989)

ANSI C78.1352 (1990)

ANSI C78.1353 (1990)

ANSI C78.1354 (1990)

ANSI C78.1355 (1989)

ANSI C78.1356 (1988)

ANSI C78.1375 (1990)

ANSI C78.1376 (1984)

ANSI C78.1377 (1990)

ANSI C78.1378 (1990)

ANSI C78.1379 (1990)

ANSI C78.1380 (1988)

ANSI C78.1381 (1989)
Dimensional and Electrical Characteristics of Fluorescent Lamps - Rapid Start Types

750 W 120 V Self-Ballasted Mercury Lamps

160 W 120 V Self-Ballasted Mercury Lamps

400 W, 100 V S51 High Pressure Sodium Lamps

Lamp.HID.HPS

$250 \mathrm{~W}, 100$ V S50 Single-Ended High

Pressure Sodium Lamps

Lamp.HID.HPS

1000 W, 250 V S52 High Pressure Sodium Lamps

Lamp.HID.HPS

70 W,52 V S62 High Pressure Sodium Lamps

Lamp.HID.HPS

100 W, 55 V S54 High Pressure Sodium Lamps

Lamp.HID.HPS

150 W, 55 V S55 High Pressure Sodium Lamps

Lamp.HID.HPS

150 W, 100 V S56 High Pressure Sodium Lamps

Lamp.HID.HPS

400 W M59 Metal Halide Lamps

Lamp.HID.MH

1000 W M47 Metal Halide Lamps

Lamp.HD.MH

175 W M57 Metal Halide Lamps

Lamp.HID.MH

250 W M58 Singled-ended Metal-Halide

Lamps

Lamp.HID.MH

1500 W M48 Metal Halide Lamps

Lamp.HD.MH

$250 \mathrm{~W} 120 \mathrm{~V}$ Self-Ballasted Mercury Lamps Specifications

Lamp.HID.MV

70 W M85 Metal Halide Lamps
Lamp.HID.MH 
Standard Ne.

ANSI C78.1500 (1985)

ANSI C78.1501 (1983)

ANSI C78.1502 (1983)

ANSI C78.180 (R1989)

ANSI C78.2 (R1984)

ANSI C78.20 (1989)

ANSI C78.21 (1989)

ANSI C78.22 (1989)

ANSI C78.23 (1989)

ANSI C78.260 (R1985)

ANSI C78.3 (R1984)

ANSI C78.375 (1991)

ANSI C78.379 (1983)

ANSI C78.380 (1984)

ANSI C78.386 (1989)

ANSI C78.387 (1987)

ANSI C78.388 (1984)

ANSI C78.40 (1985)
Standard Title

Relevant Lighting Technology

Draft - Tungsten Halogen Lamps with a

Light Center Length of $89 \mathrm{~mm}$ (3 1/2 in.)

Lamp.Incandescent

Draft - Tungsten Halogen Lamps with a

Light Center Length of $63.5 \mathrm{~mm}$ (2 1/2 in.) Lamp.Incandescent

Draft - Tungsten Halogen Lamps with a

Light Center Length of $101.6 \mathrm{~mm}$ (4 in.) Lamp.Incandescent

Specifications for Fluorescent Lamps

Starters

Starter

Dimensional and Electrical Characteristics of

Fluorescent Lamps - Preheat Start Types

Lamp.Fluorescent

Incandescent Lamps - A, G, PS, and Similar

Shapes with E26 Medium Screw Bases

Lamp.Incandescent

Incandescent Lamps - Par and R Shapes Lamp.Incandescent

Incandescent Lamps - A, G, PS, and Similar

Shapes with E39 Mogul Screw Bases

Lamp.Incandescent

Incandescent Lamps - Miscellaneous Types Lamp.Incandescent

Specification for Tubular Tungsten-Halogen

Lamps

Lamp.Incandescent

Dimensional and Electrical Characteristics of Fluorescent Lamps - Instant Start and Cold Cathode Types

Lamp.Fluorescent

Guide for Electrical Measurements of Fluorescent Lamps

Lamp.Fluorescent

Incandescent and HID Reflector Lamps -

Classification of Beam Patterns

Lamp

HID Lamps - Method of Designation

Lamp.HID

Mercury Lamps - Methods of Measuring

Characteristics

Lamp.HID.MV

Methods of Measurement of Metal-Halide-

Lamp Characteristics

Lamp.HID.MH

High Pressure Sodium Lamps - Methods of Measuring Characteristics

Lamp.HID.HPS

Specifications for Mercury Lamps 
Relevant Lighting

Standard No.

Standard Title Technology

ANSI C82.2 (R1989)

ANSI C82.3 (R1989)

ANSI C82.4 (1985)

ANSI C82.5 (1983)

ANSI C82.6 (1985)

ANSI C82.7 (R1988)

ANSI C82.8 (R1988)

BS161:1990

BS1853:Part I:1990

BS1853:Part II:1979

BS2818:Part I:1985

BS2818:Part II: 1985
Methods of Measurement of Fluorescent

Lamp Ballasts

Ballast.Fluorescent

Standard for Reference Ballasts for

Fluorescent Lamps

Ballast.Fluorescent

Ballasts for High-Intensity-Discharge and

Low-Pressure Sodium Lamps (Multiple

Supply Type)

Ballast.HID

Standard for Reference Ballasts for HID

Lamps

Ballast.HID

Methods of Measurement of High Intensity

Discharge Lamp Ballasts

Ballast.HID

Mercury Lamp Transformers - Constant

Current (Series) Supply Type

Transformer

Incandescent Filament Lamp Transformers Constant Current (Series) Supply Type

Transformer

Specification for tungsten filament lamps for general service (batch testing) Performance specifications [=EN 60 064]

Lamp.Incandescent

Specification for internationally specified lamps; characteristics, technical requirements and test methods to be used for type, batch or whole production testing. [=EN 60081 , IEC 81]

Lamp

Specification for lamps used in the UK not included in Part I.

Lamp

Specification for ballasts for use internationally; general thermal, mechanical and electrical requirements for ballasts, excluding resistance types, for use on AC power supplies up to $250 \mathrm{~V}$ at 50 or $60 \mathrm{~Hz}$ [=IEC82]

Ballast.Fluorescent

Specification for ballasts for use with lamps used in the UK not included in BS1853; specific characteristics of ballasts excluding resistance types for use on $A C$ supplies up to $250 \mathrm{~V}$ at 50 or $60 \mathrm{~Hz}$ associated with tubular fluorescent lamps with pre-heat cathodes operated with or without the aid of a starter. Ballast.Fluorescent 
Standard No.

BS3677:1989

BS3772:1990

BS4533:Part 101:1990

BS4533:Part 102.1:1990

BS4533:Part 201.2:1990

BS4533:part 201.19:1990

BS4782:1971

BS5225:Part I:1975(1985)

BS6193:1990

BS7173:1989

BS7199:1989
Standard Title

Specification for high pressure mercury vapor lamps; requirements for lamps with or without red correcting fluorescent coating operating on AC mains with ballast complying with BS4782 [=EN 60188 , $\neq$ IEC 188]

Lamp.HID.MV

Specification for starters for fluorescent lamps; general requirements for starters, including those for class II luminaires and the performance for glow starters used with preheat type starter operated tubular fluorescent lamps; to be read in conjunction with BS 1853:Part I and BS2818:Part I [=EN 60 $155: 1989, \neq$ IEC $155: 1983]$

Starter

Specification for general requirements and tests of luminaires. [=EN $60598.1, \neq$ IEC 598.1]

Luminaire.Photometry

Specification for fixed general purpose luminaires. [=EN 60 598.2.1:1989, IEC 598.2.1:1979]

Luminaire.Assembly

Specification for recessed luminaires [EN 60 598.2.2:1989] Luminaire.Assembly

Specifications for air-handling luminaires (safety requirements) [=EN 60

598.2.19:1989, $\neq$ IEC 598.2.19:1987] Luminaire.Assembly

Specification for ballasts for discharge lamps

(excluding ballasts for fluorescent lamps)

[ $\neq$ IEC 262, IEC 459, IEC 922, IEC 923]

Replaces BS3707:1964 and BS3768:1964.

Ballast.HID

Photometric measurements [ $\neq \mathrm{CIE} 24, \mathrm{CIE}$ 27]

Photometry

Specifications for high pressure sodium lamps [=EN 60 662:1989, IEC 662:1980] Lamp.HID.HPS

Specifications for self-ballasted lamps for general lighting services safety requirements. $[=$ IEC 968]

Lamp.Compact Fluorescent

Specification for self ballasted lamps for general lighting services. Performance requirements. [=[EC 969] Lamp.Compact Fluorescent 
Relevant Lighting

Standard No.

CENELEC EN 60 064-89

CENELEC EN 60081

CENELEC EN 60 155-89

CENELEC EN 60 188-88

CENELEC EN 60 357-88

CENELEC EN 60 598-1-91

CENELEC EN 60 598-2-1-89

CENELEC EN 60 598-2-2-89

CENELEC EN 60 598-2-6-89

CENELEC EN $60662-89$

CENELEC EN $60901-90$

CENELEC EN 60 920-91

CENELEC EN 60 921-91

CENELEC EN 60 922-91

CENELEC EN 60 923-91

CENELEC EN 60 926-90
Standard Title Technology

Tungsten Filament Lamps for Domestic and

Similar General Lighting Purposes -

Performance Requirements (Replaces HD

199.1-S2, HD 199.2-S2)

Lamp.Incandescent

Tubular Fluorescent Lamps for General

Lighting Service

Lamp.Fluorescent

Starters for Tubular Fluorescent Lamps (IEC

155(1983) 3rd Edition + Amendment No. 1

(1987), modified)

Starter

High Pressure Mercury Vapor Lamps

Lamp.HID.MV

Tungsten Halogen Lamps (Non-Vehicle) Lamp.Incandescent

Luminaires Part I: General Requirements and

Tests

Luminaire

Luminaires Part II: Particular Requirements

Section One - Fixed General Purpose

Luminaires

Luminaire.Assembly

Luminaires Part II: Particular Requirements

Section Two - Recessed Luminaires

Luminaire.Assembly

Luminaires Part II: Particular Requirements

Section Six - Luminaires With Built In

Transformers for Filament Lamps

Luminaire.Assembly

High Pressure Sodium Vapor Lamps

Lamp.HID.HPS

Single Capped Fluorescent Lamps - Safety and Performance Requirements

Lamp.Fluorescent

Ballasts for Tubular Fluorescent Lamps -

General and Safety Requirements

Ballast.Fluorescent

Ballasts for Tubular Fluorescent Lamps -

Performance Requirements

Ballast.Fluorescent

Ballasts for Discharge Lamps (Excluding Tubular Fluorescent Lamps) General and Safety Requirements

Ballast.HID

Ballasts for Discharge Lamps (Excluding

Tubular Fluorescent Lamps) - Performance Requirements

Ballast.HID

Starting Devices (Other than Glow Starters)

General and Safety Requirements 
Standard No

CENELEC EN 60 927-90

CENELEC EN 60 928-91

CENELEC HD 302-75

CENELEC HD 594-S1-91

CIE 24 (TC-2.4) 1973

CIE 25 (TC 1.2) 1973

CSA C22.2 No. 9 (1968)

CSA C22.2 No. 84

IEC 64 (1987)

IEC 81 (1984)

IEC 82 (1984)

IEC 155 (1983)

IEC 162 (1972)

IEC 188 (1974)

IEC 262 (1969)

IEC 357 (1982)

IEC 458 (1982)

IEC 598-1 (1986)

IEC 598-2-1 (1979)
Standard Title

Starting Devices (Other than Glow Starters)

Performance Requirements

Starter

AC Supplied Electronic Ballasts for Tubular

Fluorescent Lamps - General and Safety

Requirements

Ballast.Fluorescent

Transistorized Ballasts for Fluorescent

Lamps

Ballast.Fluorescent

Self-ballasted Lamps for General Lighting

Services - Performance Requirements

Lamp.Compact Fluorescent

Photometry of Indoor Type Luminaires with

Tubular Fluorescent Lamps

Photometry.Luminaire.Fluorescent

Procedures for the Measurement of

Luminous Flux of Discharge Lamps and for

their Calibration as Working Standards

Photometry.Lamp

Electric Lighting Fixtures

Luminaire

Incandescent Lamps

Lamp.Incandescent

Tungsten Filament Lamps

Lamp.Incandescent

Tubular Fluorescent Lamps

Lamp.Fluorescent

Ballasts for Tubular Fluorescent Lamps

Ballast.Fluorescent

Starters for Tubular Fluorescent Lamps

Starter

Luminaires for Tubular Fluorescent Lamps

Luminaire.Assembly

High Pressure Mercury Vapor Lamps

Lamp.HID.MV

Ballasts for High Pressure Mercury Vapor

Lamps

Ballast.HID.MV

Tungsten Halogen Lamps (non vehicle)

Lamp.Incandescent

Transistorized Ballasts for Fluorescent

Lamps

Ballast.Fluorescent

Luminaires - General Requirements and Tests

Luminaire.Assembly

Fixed General Purpose Luminaires 
Relevant Lighting

Standard No.

Standard Title Technology

Luminaires with Built-in Transformers for Filament Lamps

Luminaire.Assembly

IEC 662 (1980)

High Pressure Sodium Lamps

Lamp.HID.HPS

IEC 882 (1986)

Pre-Heat Requirements for Starterless

Tubular Fluorescent Lamps

Lamp.Fluorescent

IEC 901 (1987)

Single-Capped Fluorescent Lamps -- Safety and Performance Requirements

Lamp.Fluorescent

IEC 920 (1990)

Ballasts for Tubular Fluorescent Lamps

Ballast.Fluorescent

IEC 921 (1988)

Ballasts for Tubular Fluorescent Lamps -

Performance Requirements

Ballast.Fluorescent

IEC 922 (1989)

Ballasts for Discharge Lamps (Excluding

Tubular Fluorescent Lamps) - General and

Safety Requirements

Ballast.HID

IEC 923 (1988)

Ballasts for Discharge Lamps (Excluding

Tubular Fluorescent Lamps) - Performance

Requirements

Ballast.HID

IEC 926 (1990)

Starting Devices (Other than Glow Starters)

Starter

IEC 927 (1988)

Starting Devices (Other than Glow

Starters)/Performance Requirements

Starter

IEC 928 (1990)

A.C. Supplied Electronic Ballasts for Tubular

Fluorescent Lamps

Ballast.Fluorescent

IEC 968 (1988)

Self-Ballasted Lamps for General Lighting -

Safety Requirements

Lamp.Compact Fluorescent

IEC 969 (1988)

Self-Ballasted Lamps for General Lighting

Services

Lamp.Compact Fluorescent

IES LM-20 (1983)

Approved Method for Photometric Measuring

and Reporting Tests on Reflector Type

Lamps

Photometry.Lamp.Incandescent.Reflector

IES LM-27 (1967)

Approved Method for the Photometric

Testing of Filament Type Luminaires for

General Lighting Service

Photometry.Lamp.Incandescent.General Service 
Standard No.

IES LM-41 (1985)

IES LM-45 (1981)

IES LM-46 (1985)

IES LM-51 (1984)

IES LM-66 (1991)

IES LM-9 (1981)

JIS C7501

JS C7527

JIS C7604

JIS C7607

JS C7608

JIS C7613

JIS C7801

JS C8105

JIS C8108

JIS C8110

JS C8116
Approved Method for Photometric Testing of

Indoor Fluorescent Luminaires

Photometry.Luminaire.Fluorescent

Approved Method for Electrical and

Photometric Measurements of General

Service Incandescent Filament Lamps

Lamp.Incandescent

Approved Method for Photometric Testing of

Indoor Luminaires Using High Intensity

Discharge or Incandescent Filament Lamps

Photometry.Luminaire.Incandescent/HID

Approved Method for Photometric

Measurements of High Intensity Discharge

Lamps

Photometry.Lamp.HID

Electrical and Photometric Measurements of single-ended compact fluorescent lamps

Photometry.Lamp.Compact Fluorescent

Approved Method for Electrical and

Photometric Measurements of Fluorescent

Lamps

Photometry.Lamp.Fluorescent

Lamps - general lighting service

Lamp.Incandescent

Lamps - halogen

Lamp.Incandescent

Lamps - high pressure mercury

Lamp.HID.HPS

Photometric measurement methods (std) fluorescent lamps

Photometry.Lamp.Fluorescent

Photometric measurement methods (std) mercury vapor

Photometry.Lamp.HID.MV

Lamps - standard incandescent, photometric

measurement

Photometry.Lamp.Incandescent

Lamps - testing methods

Lamp

Luminaires

Luminaire

Ballasts - fluorescent lamps

Ballast.Fluorescent

Ballasts - high pressure mercury vapor lamps

Ballast.HID.MV

Lamps - incandescent

Lamp.Incandescent 
Standard No

ANSI C78.379 (1983)

BS1853:Part I:1990

BS1853:Part II:1979

JIS C7801

ANSI C78.20 (1989)

ANSI C78.21 (1989)

ANSI C78.22 (1989)

ANSI C78.23 (1989)

ANSI C78.260 (R1985)

ANSI C78.1500 (1985)

ANSI C78.1501 (1983)

ANSI C78.1502 (1983)

BS161:1990

CENELEC EN 60 064-89
Standard Title

Relevant Lighting Technology

Incandescent and HID Reflector Lamps -

Classification of Beam Patterns

Lamp

Specification for internationally specified lamps; characteristics, technical requirements and test methods to be used for type, batch or whole production testing. [ $=\mathrm{EN} 60081, \mathrm{IEC}$ 81]

Specification for lamps used in the UK not included in Part I.

Lamps - testing methods

Lamp

Incandescent Lamps - A, G, PS, and Similar Shapes with E26 Medium Screw Bases Lamp.Incandescent

Incandescent Lamps - Par and R Shapes Lamp.Incandescent

Incandescent Lamps - A, G, PS, and Similar Shapes with E39 Mogul Screw Bases

Lamp.Incandescent

Incandescent Lamps - Miscellaneous Types Lamp.Incandescent Specification for Tubular Tungsten-Halogen Lamps

Lamp.Incandescent

Draft - Tungsten Halogen Lamps with a

Light Center Length of $89 \mathrm{~mm}$ (3 $1 / 2 \mathrm{in}$.) Lamp.Incandescent

Draft - Tungsten Halogen Lamps with a

Light Center Length of $63.5 \mathrm{~mm}$ (2 1/2 in.) Lamp.Incandescent

Draft - Tungsten Halogen Lamps with a

Light Center Length of 101.6 mm (4 in.) Lamp.Incandescent

Specification for tungsten filament lamps for general service (batch testing) Performance specifications [=EN 60 064]

Lamp.Incandescent

Tungsten Filament Lamps for Domestic and Similar General Lighting Purposes Performance Requirements (Replaces HD 199.1-S2, HD 199.2-S2) 
Standard No.

CENELEC EN 60 357-88

CSA C22.2 No. 84

IEC 64 (1987)

IEC 357 (1982)

IES LM-45 (1981)

JIS C7501

JIS C7527

JIS C8116

ANSI C78.1 (1978)

ANSI C78.2 (R1984)

ANSI C78.3 (R1984)

ANSI C78.375 (1991)

CENELEC EN 60081

CENELEC EN 60 901-90

IEC 81 (1984)

IEC 882 (1986)

IEC 901 (1987)

BS7173:1989

BS7199:1989
Standard Title

Relevant Lighting Technology

Tungsten Halogen Lamps (Non-Vehicle) Lamp.Incandescent

Incandescent Lamps

Lamp.Incandescent

Tungsten Filament Lamps

Lamp.Incandescent

Tungsten Halogen Lamps (non vehicle) Lamp.Incandescent

Approved Method for Electrical and

Photometric Measurements of General

Service Incandescent Filament Lamps

Lamp.Incandescent

Lamps - general lighting service

Lamp.Incandescent

Lamps - halogen

Lamp.Incandescent

Lamps - incandescent

Lamp.Incandescent

Dimensional and Electrical Characteristics of Fluorescent Lamps - Rapid Start Types

Lamp.Fluorescent

Dimensional and Electrical Characteristics of Fluorescent Lamps - Preheat Start Types

Lamp.Fluorescent

Dimensional and Electrical Characteristics of Fluorescent Lamps - Instant Start and Cold Cathode Types

Lamp.Fluorescent

Guide for Electrical Measurements of

Fluorescent Lamps

Lamp.Fluorescent

Tubular Fluorescent Lamps for General Lighting Service

Lamp.Fluorescent

Single Capped Fluorescent Lamps - Safety and Performance Requirements

Lamp.Fluorescent

Tubular Fluorescent Lamps

Lamp.Fluorescent

Pre-Heat Requirements for Starterless

Tubular Fluorescent Lamps

Lamp.Fluorescent

Single-Capped Fluorescent Lamps -- Safety and Performance Requirements

Lamp.Fluorescent

Specifications for self-ballasted lamps for general lighting services safety requirements. [=IEC 968]

Lamp.Compact Fluorescent

Specification for self ballasted lamps for general lighting services. Performance requirements. [=IEC 969]

Lamp.Compact Fluorescent 
CENELEC HD 594-S1-91

IEC 968 (1988)

IEC 969 (1988)

ANSI C78.380 (1984)

ANSI C78.386 (1989)

ANSI C78.40 (1985)

ANSI C78.1341 (1990)

ANSI C78.1342 (1985)

ANSI C78.1380 (1988)

BS3677:1989

CENELEC EN 60 188-88

IEC 188 (1974)

JIS C7604

ANSI C78.387 (1987)

ANSI C78.1375 (1990)

ANSI C78.1376 (1984)

ANSI C78.1377 (1990)

ANSI C78.1378 (1990)

ANSI C78.1379 (1990)
Self-ballasted Lamps for General Lighting

Services - Performance Requirements

Lamp.Compact Fluorescent

Self-Ballasted Lamps for General Lighting -

Safety Requirements Lamp.Compact Fluorescent

Self-Ballasted Lamps for General Lighting

Services

Lamp.Compact Fluorescent

HID Lamps - Method of Designation

Lamp.HII

Mercury Lamps - Methods of Measuring

Characteristics

Lamp.HID.MV

Specifications for Mercury Lamps

Lamp.HID.MV

750 W 120 V Self-Ballasted Mercury Lamps

Lamp.HID.MV

160 W 120 V Self-Ballasted Mercury Lamps

Lamp.HID.MV

250 W 120V Self-Ballasted Mercury Lamps Specifications

Lamp.HID.MV

Specification for high pressure mercury vapor lamps; requirements for lamps with or without red correcting fluorescent coating operating on $\mathrm{AC}$ mains with ballast complying with BS4782 [=EN 60188 , \#IEC 188]

Lamp.HIID.MV

High Pressure Mercury Vapor Lamps

Lamp.HID.MV

High Pressure Mercury Vapor Lamps

Lamp.HID.MV

Lamps - high pressure mercury

Lamp.HID.MV

Methods of Measurement of Metal-HalideLamp Characteristics

Lamp.HID.MH

400 W M59 Metal Halide Lamps

Lamp.HID.MH

1000 W M47 Metal Halide Lamps

Lamp.HID.MH

175 W M57 Metal Halide Lamps

Lamp.HID.MH

250 W M58 Singled-ended Metal-Halide Lamps

Lamp.HID.MH

1500 W M48 Metal Halide Lamps 
Standard No.

ANSI C78.1381 (1989)

ANSI C78.388 (1984)

ANSI C78.1350 (1990)

ANSI C78.1351 (1989)

ANSI C78.1352 (1990)

ANSI C78.1353 (1990)

ANSI C78.1354 (1990)

ANSI C78.1355 (1989)

ANSI C78.1356 (1988)

BS6193:1990

CENELEC EN $60662-89$

IEC 662 (1980)

ANSI C82.2 (R1989)

ANSI C82.3 (R1989)

BS2818:Part I:1985
Standard Title

70 W M85 Metal Halide Lamps Technology

Lamp.HID.MH

High Pressure Sodium Lamps - Methods of Measuring Characteristics

Lamp.HID.HPS

400 W, 100 V S51 High Pressure Sodium Lamps

Lamp.HID.HPS

$250 \mathrm{~W}, 100 \mathrm{~V}$ S50 Single-Ended High

Pressure Sodium Lamps

Lamp.HID.HPS

1000 W, 250 V S52 High Pressure Sodium Lamps

Lamp.HID.HPS

70 W,52 V S62 High Pressure Sodium Lamps

Lamp.HID.HPS

100 W, 55 V S54 High Pressure Sodium

Lamps

Lamp.HID.HPS

150 W, 55 V S55 High Pressure Sodium Lamps

Lamp.HID.HPS

150 W, 100 V S56 High Pressure Sodium Lamps

Lamp.HID.HPS

Specifications for high pressure sodium lamps [=EN 60 662:1989, IEC 662:1980]

High Pressure Sodium Vapor Lamps

High Pressure Sodium Lamps

Methods of Measurement of Fluorescent Lamp Ballasts

Standard for Reference Ballasts for Fluorescent Lamps

Specification for ballasts for use internationally; general thermal, mechanical and electrical requirements for ballasts, excluding resistance types, for use on AC power supplies up to $250 \mathrm{~V}$ at 50 or $60 \mathrm{~Hz}$ [=IEC82]
Ballast.Fluorescent

Ballast.Fluorescent

Lamp.HID.HPS

Lamp.HID.HPS

Lamp.HID.HPS

Ballast.Fluorescent 
Standard No

BS2818:Part II: 1985

CENELEC EN 60 920-91

CENELEC EN 60 921-91

CENELEC EN 60 928-91

CENELEC HD 302-75

IEC 82 (1984)

IEC 458 (1982)

IEC 920 (1990)

IEC 921 (1988)

IEC 928 (1990)

JIS C8108

ANSI C82.4 (1985)

ANSI C82.5 (1983)

ANSI C82.6 (1985)

BS4782:1971
Standard Title

Relevant Lighting Technology

Specification for ballasts for use with lamps used in the UK not included in BS1853; specific characteristics of ballasts excluding resistance types for use on AC supplies up to $250 \mathrm{~V}$ at 50 or $60 \mathrm{~Hz}$ associated with tubular fluorescent lamps with pre-heat cathodes operated with or without the aid of a starter. Ballast.Fluorescent

Ballasts for Tubular Fluorescent Lamps General and Safety Requirements

Ballast.Fluorescent

Ballasts for Tubular Fluorescent Lamps Performance Requirements

Ballast.Fluorescent

AC Supplied Electronic Ballasts for Tubular Fluorescent Lamps - General and Safety Requirements

Ballast.Fluorescent

Transistorized Ballasts for Fluorescent Lamps

Ballast.Fluorescent

Ballasts for Tubular Fluorescent Lamps

Ballast.Fluorescent

Transistorized Ballasts for Fluorescent Lamps

Ballast.Fluorescent

Ballasts for Tubular Fluorescent Lamps

Ballast.Fluorescent

Ballasts for Tubular Fluorescent Lamps Performance Requirements

Ballast.Fluorescent

A.C. Supplied Electronic Ballasts for Tubular

Fluorescent Lamps

Ballast.Fluorescent

Ballasts - fluorescent lamps

Ballast.Fluorescent

Ballasts for High-Intensity-Discharge and

Low-Pressure Sodium Lamps (Multiple

Supply Type)

Ballast.HID

Standard for Reference Ballasts for HID Lamps

Ballast.HID

Methods of Measurement of High Intensity

Discharge Lamp Ballasts

Ballast.HID

Specification for ballasts for discharge lamps

(excluding ballasts for fluorescent lamps)

[ $\neq$ IEC 262, IEC 459, IEC 922, IEC 923]

Replaces BS3707:1964 and BS3768:1964. 
Standard No.

CENELEC EN 60 922-91

CENELEC EN 60 923-91

IEC 922 (1989)

IEC $923(1988)$

IEC 262 (1969)

JS C8110

ANSI C78.180 (R1989)

BS3772:1990

CENELEC EN 60 155-89

CENELEC EN 60 926-90

CENELEC EN 60 927-90

IEC 155 (1983)

IEC 926 (1990)

IEC 927 (1988)
Standard Title

Relevant Lighting

Ballasts for Discharge Lamps (Excluding

Tubular Fluorescent Lamps) General and

Safety Requirements

Ballast.HID

Ballasts for Discharge Lamps (Excluding

Tubular Fluorescent Lamps) - Performance

Requirements

Ballast.HID

Ballasts for Discharge Lamps (Excluding

Tubular Fluorescent Lamps) - General and

Safety Requirements

Ballast.HID

Ballasts for Discharge Lamps (Excluding

Tubular Fluorescent Lamps) - Performance

Requirements

Ballast.HID

Ballasts for High Pressure Mercury Vapor Lamps

Ballast.HID.MV

Ballasts - high pressure mercury vapor lamps

Ballast.HID.MV

Specifications for Fluorescent Lamps

Starters

Starter

Specification for starters for fluorescent lamps; general requirements for starters, including those for class II luminaires and the performance for glow starters used with preheat type starter operated tubular fluorescent lamps; to be read in conjunction with BS1853:Part I and BS2818:Part I [=EN 60 $155: 1989, \neq$ IEC $155: 1983$ ]

Starter

Starters for Tubular Fluorescent Lamps (IEC 155(1983) 3rd Edition + Amendment No. 1 (1987), modified)

Starter

Starting Devices (Other than Glow Starters)

General and Safety Requirements

Starter

Starting Devices (Other than Glow Starters)

Performance Requirements

Starter

Starters for Tubular Fluorescent Lamps

Starter

Starting Devices (Other than Glow Starters)

Starter

Starting Devices (Other than Glow

Starters)/Performance Requirements 
Standard No.

ANSI C82.7 (R1988)

ANSI C82.8 (R1988)

BS4533:Part 101:1990

CENELEC EN 60 598-1-91

CSA C22.2 No. 9 (1968)

JIS C8105

BS4533:Part 102.1:1990

BS4533:Part 201.2:1990

BS4533:part 201.19:1990

CENELEC EN 60 598-2-1-89

CENELEC EN 60 598-2-2-89

CENELEC EN 60 598-2-6-89

IEC 162 (1972)

IEC 598-1 (1986)

IEC 598-2-1 (1979)

IEC 598-2-2 (1979)

IEC 598-2-6 (1979)
Standard Title

Mercury Lamp Transformers - Constant

Current (Series) Supply Type

Relevant Lighting Technology

Transformer

Incandescent Filament Lamp Transformers -

Constant Current (Series) Supply Type

Transformer

Specification for general requirements and

tests of luminaires. [ $=$ EN $60598.1, \neq$ IEC

598.1]

Luminaire

Luminaires Part I: General Requirements and

Tests

Luminaire

Electric Lighting Fixtures

Luminaire

Luminaires

Luminaire

Specification for fixed general purpose luminaires. [=EN 60 598.2.1:1989, IEC 598.2.1:1979]

Luminaire.Assembly

Specification for recessed luminaires [EN 60 598.2.2:1989]

Luminaire.Assembly

Specifications for air-handling luminaires

(safety requirements) [=EN 60

598.2.19:1989, $\neq$ IEC 598.2.19:1987] Luminaire.Assembly

Luminaires Part II: Particular Requirements

Section One - Fixed General Purpose

Luminaires

Luminaire.Assembly

Luminaires Part II: Particular Requirements

Section Two - Recessed Luminaires

Luminaire.Assembly

Luminaires Part II: Particular Requirements

Section Six - Luminaires With Built In

Transformers for Filament Lamps

Luminaire.Assembly

Luminaires for Tubular Fluorescent Lamps Luminaire.Assembly

Luminaires - General Requirements and

Tests

Luminaire.Assembly

Fixed General Purpose Luminaires

Luminaire.Assembly

Recessed Luminaires

Luminaire.Assembly

Luminaires with Built-in Transformers for Filament Lamps

Luminaire.Assembly 
Standard No.

BS5225:Part I:1975(1985)

CIE 25 (TC 1.2) 1973

JIS C7613

IES LM-27 (1967)

IES LM-20 (1983)

IES LM-9 (1981)

JIS C7607

IES LM-66 (1991)

IES LM-51 (1984)

JIS C7608

IES LM-46 (1985)

IES LM-41 (1985)

CIE 24 (TC-2.4) 1973
Standard Title

Relevant Lighting Technology

Photometric measurements [ $\neq \mathrm{CIE} 24, \mathrm{CIE}$ 27]

Photometry

Procedures for the Measurement of

Luminous Flux of Discharge Lamps and for

their Calibration as Working Standards

Photometry.Lamp

Lamps - standard incandescent, photometric

measurement

Photometry.Lamp.Incandescent

Approved Method for the Photometric

Testing of Filament Type Luminaires for

General Lighting Service

Photometry.Lamp.Incandescent.General Service

Approved Method for Photometric Measuring

and Reporting Tests on Reflector Type

Lamps

Photometry.Lamp.Incandescent.Reflector

Approved Method for Electrical and

Photometric Measurements of Fluorescent

Lamps

Photometry.Lamp.Fluorescent

Photometric measurement methods (std) -

fluorescent lamps

Photometry.Lamp.Fluorescent

Electrical and Photometric Measurements of single-ended compact fluorescent lamps

Photometry.Lamp.Compact Fluorescent

Approved Method for Photometric

Measurements of High Intensity Discharge

Lamps

Photometry.Lamp.HIID

Photometric measurement methods (std) -

mercury vapor

Photometry.Lamp.HID.MV

Approved Method for Photometric Testing of

Indoor Luminaires Using High Intensity

Discharge or Incandescent Filament Lamps

Photometry.Luminaire.Incandescent/HID

Approved Method for Photometric Testing of Indoor Fluorescent Luminaires

Photometry.Luminaire.Fluorescent

Photometry of Indoor Type Luminaires with

Tubular Fluorescent Lamps Photometry.Luminaire.Fluorescent 


\section{Glossary}

ballast a device used with an electric-discharge lamp to obtain the necessary circuit conditions (voltage, current and wave form) for starting and operating. (Kaufman, 1984, p. 1-4)

ballast factor the fractional flux of a lamp(s) operated on a ballast compared to the flux when operated on the reference ballasting specified for rating lamp lumens. (Kaufman, 1984, p. 14)

candlepower (intensity) distribution curve a curve, generally polar, representing the variation of luminous intensity of a lamp or luminaire in a plane through the light center. (Kaufman, 1984, p. 1-6)

coefficient of utilization, (CU) the ratio of the luminous flux (lumens) from a luminaire calculated as received on the work-plane to the luminous flux emitted by the luminaire's lamps alone. (Kaufman, 1984, p. 1-8)

color rendering index (of a light source) (CRI) measure of the degree of color shift objects undergo when illuminated by the light source as compared with the color of those same objects when illuminated by a reference source of comparable color temperature. (Kaufman, 1984, p. 1-8)

correlated color temperature (of a light source) the absolute temperature of a blackbody whose chromaticity most nearly resembles that of the light source. (Kaufman, 1984, p. 1-9)

fluorescent lamp a low-pressure mercury electric-discharge lamp in which a fluorescing coating (phosphor) transforms some of the ultraviolet energy generated by the discharge into light. (Kaufman, 1984, p. 1-13)

high intensity discharge (HID) lamp an electric discharge lamp in which the light producing arc is stabilized by wall temperature, and the arc tube has a bulb wall loading in excess of three watts per square centimeter. HID lamps include groups of lamps known as mercury, metal halide, and high pressure sodium. (Kaufman, 1984, p. 1-16)

illuminance the density of the luminous flux incident on a surface; it is the quotient of the luminous flux by the area of the surface when the latter is uniformly illuminated. (Kaufman, 1984, p. 1-16)

lamp lumen depreciation factor, (LLD) the multiplier to be used in illumination calculations to relate the initial rated output of light sources to the anticipated minimum rated output based on the relamping program to be used. (Kaufman, 1984, p. 1-18)

light loss factor, (LLF) a factor used in calculating illuminance after a given period of time and under given conditions. It takes into account temperature and voltage variations, dirt accumulation on luminaire and room surfaces, lamp depreciation, maintenance procedures and atmospheric conditions. (Kaufman, 1984, p. 1-18)

light-watt radiation weighted by the spectral luminous efficiency for photopic vision. (Kaufman, 1984, p. 1-18) 
luminaire a complete lighting unit consisting of a lamp or lamps together with the parts designed to distribute the light, to position and protect the lamps and to connect the lamps to the power supply. (Kaufman, 1984, p. 1-19)

luminaire dirt depreciation factor, (LDD) the multiplier to be used in illuminance calculations to relate the initial illuminance provided by clean, new luminaires to the reduced illuminance that they will provide due to dirt collection on the luminaires at the time at which it is anticipated that cleaning procedures will be instituted. (Kaufman, 1984, p. 1-19)

luminaire efficiency the ratio of luminous flux (lumens) emitted by a luminaire to that emitted by the lamp or lamps used therein. (Kaufman, 1984, p. 1-19)

luminous efficacy of a source of light the quotient of the total luminous flux emitted by the total lamp power input. It is expressed in lumens per watt. (Kaufman, 1984, p. 1-21)

luminous flux the time rate of flow of light. (Kaufman, 1984, p. 1-21)

mercury lamp a high intensity discharge (HID) lamp in which the major portion of the light is produced by radiation from mercury operating at a partial pressure in excess of $105 \mathrm{~Pa}$ (approximately 1 atmosphere). (Kaufman, 1984, p. 1-21)

metal halide lamp a high intensity discharge (HID) lamp in which the major portion of the light is produced by radiation of metal halides and their products of dissociation-possibly in combination with metallic vapors such as mercury. (Kaufman, 1984, p. 1-21)

reference ballast a ballast specially constructed to have certain prescribed characteristics for use in testing electric discharge lamps and other ballasts. (Kaufman, 1984, p. 1-25)

room surface dirt depreciation, (RSDD) the fractional loss of task illuminance due to dirt on the room surface. (Kaufman, 1984, p. 1-27) 


